\title{
Strength and Ductility Improvement of Recycled Aggregate Concrete by Polyester FRP-PVC Tube Confinement
}

\author{
Chang Gao ${ }^{1}$, Liang Huang ${ }^{1 *}$, Libo Yan ${ }^{2,3 *}$, Ruoyu $\operatorname{Jin}^{4}$ and Bohumil Kasal ${ }^{2,3}$ \\ ${ }^{1}$ College of Civil Engineering, Hunan University, Changsha 410082, China \\ ${ }^{2}$ Centre for Light and Environmentally-Friendly Structures, Fraunhofer Wilhelm-Klauditz-Institut WKI, \\ Bienroder Weg 54E, Braunschweig 38108, Germany \\ ${ }^{3}$ Department of Organic and Wood-Based Construction Materials, Technical University of \\ Braunschweig, Hopfengarten 20, 38102 Braunschweig, Germany \\ ${ }^{4}$ School of Environment and Technology, University of Brighton, Cockcroft Building 616, \\ Brighton, UK \\ *Corresponding authors: Liang Huang. Email: lianghuanghnu@gmail.com and Libo Yan. Email: \\ 1.yan@tu-braunschweig.de
}

\begin{abstract}
In literature, studies on recycled aggregate concrete (RAC) with recycled aggregates (RAs) originated from clay brick waste are rare, which is mainly attributed to the much lower compressive strength of the RAC with recycled clay brick aggregates (RAC-RCBA) when comparing with its normal aggregate concrete (NAC) counterpart. Nowadays it is well known that fiber reinforced polymer (FRP) composites as lateral confining materials can improve the strength and ductility of NAC significantly. In this study, FRP confining materials were used to improve the compressive strength and ductility of the RAC-RCBA. Compared with conventional synthetic glass or carbon FRP composites, polyester FRP (PFRP) and Polyvinyl chloride (PVC) are much cheaper and show much larger tensile deformation capacity. Therefore, this study investigated the axial compressive behavior of PFRP and PVC hybrid tube encased RAC-RCBA (i.e., shortened as PFRP-PVC-RAC-RCBA) structure. This PFRPPVC-RAC-RCBA system consisted of an RAC-RCBA core, encased by a PVC tube directly and the PVC tube was further confined with a PFRP tube (i.e. PFRP tube-PVC-RAC-RCBA specimen) or PFRP strips (i.e. PFRP strip-PVC-RAC-RCBA) at the outermost layer. Uniaxial compression tests were performed on 33 PFRP-PVC-RAC-RCBA and 39 unconfined RACRCBA specimens to evaluate and compare the axial compressive behavior of PVC tube encased RAC-RCBA, PFRP tube encased RAC-RCBA, PFRP tube-PVC-RAC-RCBA and PFRP strip-PVC-RAC-RCBA columns. The tested variables included the number of PFRP layers (3-, 6- and 9-layer), the type of PFRP confinement (in the configuration of tube or strips) and the spacing of the PFRP strips $(25$ and $50 \mathrm{~mm}$ ). The tested results demonstrated that the PFRP-PVC hybrid confining system enhanced the compressive strength and axial and lateral deformations of the RAC-RCBA pronouncedly, e.g. the increase in strength ranged from $4.5 \%$ to $39.6 \%$. The enhancement in strength and deformations was increased with a thicker PFRP tube or strip. Both the PFRP tube-PVC-RAC-RCBA and PFRP strip-PVCRAC-RCBA showed the similar axial compressive stress-stain behaviors. In addition, the comparison of PFRP tube-PVC-RAC-RCBA with the glass/carbon FRP tube-RAC-RCBA indicated that the GFRP and CFRP tube confinement resulted in much larger enhancement in ultimate compressive strength of RAC-RCBA due to the much larger tensile modulus and strength of these G/CFRP composites. However, PFRP-PVC tube confinement led to much larger axial deformation of the RAC-RCBA compared with the G/CFRP tube confinement due to the much larger tensile strain of the PFRP and PVC material. Furthermore, designoriented compressive stress-strain models were developed for PFRP-PVC-RAC-RCBA specimens.
\end{abstract}

Keywords: Recycled aggregate concrete (RAC); Recycled clay brick aggregates (RCBA); Polyester fiber reinforced polymer (PFRP); PVC; Dual confinement; Compressive behavior 


\begin{tabular}{|c|c|c|c|}
\hline$R A C$ & Recycled aggregate concrete & $d$ & Diameter of cylindrical core concrete \\
\hline$R C B A$ & Recycled clay brick aggregate & $f_{c o}$ & $\begin{array}{l}\text { Peak stress of unconfined RAC- } \\
\text { RCBA }\end{array}$ \\
\hline$R A s$ & Recycled aggregates & $\varepsilon_{\mathrm{co}}$ & $\begin{array}{l}\text { Axial strain of unconfined RAC- } \\
\text { RCBA at peak stress }\end{array}$ \\
\hline$N A C$ & Natural aggregate concrete & $f_{c t}$ & Peak stress of confined specimens \\
\hline NAs & Natural aggregates & $\varepsilon_{\mathrm{ct}}$ & $\begin{array}{l}\text { Lateral strain of confined specimens at } \\
\text { peak stress }\end{array}$ \\
\hline$F R P$ & Fiber reinforced polymer & $\varepsilon_{l}$ & $\begin{array}{l}\text { Axial strain of confined specimens at } \\
\text { peak stress }\end{array}$ \\
\hline PFRP & Polyester FRP & $f_{l}$ & Lateral confining pressure of FRP \\
\hline GFRP & Glass FRP & $f_{c u}$ & $\begin{array}{l}\text { Ultimate stress of the confined } \\
\text { specimens }\end{array}$ \\
\hline$C F R P$ & Carbon FRP & $\varepsilon_{\mathrm{cu}}$ & $\begin{array}{l}\text { Ultimate axial strain of the confined } \\
\text { specimens at ultimate stress }\end{array}$ \\
\hline$A F R P$ & Aramid FRP & $\mu$ & Ductility indices \\
\hline$B F R P$ & Basalt FRP & $\mu_{t}$ & Dilation rate \\
\hline$P V C$ & Poly Vinyl chloride & $f_{l}^{\prime}$ & $\begin{array}{l}\text { Lateral confining pressure of the } \\
\text { composite confinement on concrete } \\
\text { core }\end{array}$ \\
\hline$R C$ & Reinforced concrete & $f_{l f}$ & $\begin{array}{l}\text { Effective lateral confining pressure } \\
\text { provided by PFRP }\end{array}$ \\
\hline$A V G$ & Average value & $f_{l p}$ & $\begin{array}{l}\text { Lateral confining pressure provided } \\
\text { by PVC }\end{array}$ \\
\hline $\mathrm{COV}$ & Coefficients of variation & $E_{p v c}$ & Elastic modulus of the PVC tube \\
\hline$S D$ & Standard deviation & $\varepsilon_{p v c}$ & $\begin{array}{l}\text { Tensile strain in the hoop direction of } \\
\text { the PVC tube }\end{array}$ \\
\hline$D_{l}$ & Diameter of core RAC & $t_{p v c}$ & Thickness of the PVC tube \\
\hline$D_{2}$ & Diameter of PVC tube & $n$ & Number of PFRP strips \\
\hline$H$ & Height of concrete cylinders & $k_{e}$ & $\begin{array}{l}\text { Effective confining coefficient of the } \\
\text { PFRP strip }\end{array}$ \\
\hline$E_{f r p}$ & Elastic modulus of PFRP tube & Ae & $\begin{array}{l}\text { Effective confining area of the core } \\
\text { concrete }\end{array}$ \\
\hline$\varepsilon_{f r p}$ & $\begin{array}{l}\text { Tensile strain in the hoop direction of } \\
\text { PFRP tube }\end{array}$ & $A$ & $\begin{array}{l}\text { Gross area of specimens including the } \\
\text { core concrete and external hybrid tube }\end{array}$ \\
\hline$t_{f r p}$ & Thickness of PFRP tube & $m$ & $\begin{array}{l}\text { Number of zone without confinement } \\
\text { among PFRP strip }\end{array}$ \\
\hline$t_{\text {frp }}$ & $\begin{array}{l}\text { Equivalent PFRP thickness for PFRP } \\
\text { strip-PVC-RAC-RCBA cylinders }\end{array}$ & $s$ & Spacing distance of the PFRP strip \\
\hline$b_{f r p}$ & Width of PFRP strip & $\lambda$ & $\begin{array}{l}\text { Related eigenvalue of ultimate stress } \\
\text { and the elastic modulus of confined } \\
\text { materials and core concrete }\end{array}$ \\
\hline$f_{l}$ & Lateral confining pressure & $E_{c}$ & Elastic modulus of the RAC-RCBA \\
\hline$f_{\text {frp }}$ & Tensile strength of FRP & $E_{l}$ & $\begin{array}{l}\text { Effective lateral confining stiffness of } \\
\text { the hybrid PFRP-PVC tube }\end{array}$ \\
\hline$t_{f r p}$ & Thickness of FRP & & \\
\hline
\end{tabular}

55 The process of urbanization generated a large amount of construction and demolition waste 56 (CDW) which caused environmental pollution issues and difficulties to dispose those waste. 
An abundant utilization of recycled aggregate concrete (RAC) could not only solve the disposal issue of CDW but also reduce the consumption of natural resources [1-2]. RAC is an environmentally friendly concrete in which part or all the natural aggregates (NAs) are replaced by recycled aggregates (RAs) [2]. RAs are mostly sorted from crushed CDW. In literature, most research of RAC focused on the use of RAs originating from old concrete blocks. Indeed, except for the old concrete waste, clay brick waste also accounted for a large portion of the CDW, i.e. up to 30-40\% [3-4]. So, if recycled clay brick aggregates (RCBA) originated from clay brick wastes can be used to produce RAC as structural concrete, this will be a significant step for the development of sustainable concrete industry. However, RCBA typically exhibited weaknesses when being used to produce RAC, i.e., high porosity and variation in quality [5-9]. For example, because of the high porosity of RCBA, the crushing index and water absorption of RAs can be significantly larger than those of NAs, i.e. the crushing index and water absorption of RCBA might be $60 \%$ and $700 \%$ larger than those of NAs, respectively. This can cause poor mechanical properties of the resulting RAC such as the reduction in load carrying capacity and stiffness and increase in creep and shrinkage of the RAC [5-7]. In addition, the complexity of RCBAs source results in the dispersion and uncertainty of the mechanical properties of RAC in the aspects of flow ability, strength and durability [8]. Thus, the mechanical properties of RAC-RCBA should be improved to expand the range of their application considering the social and environmental benefits to use RCBA [9].

It has been widely accepted that confined concrete is an effective way to improve mechanical properties of concrete [10-14]. Fiber reinforced polymer (FRP) composites such as glass FRP (GFRP), carbon FRP (CFRP), and other FRP composites, i.e., basalt FRP (BFRP) [71] and steel fibers [72], as one of the most effective confining materials for concrete, have been widely used to improve the strength and ductility of natural aggregate concrete (NAC). Concrete filled FRP tube (CFFT) is a hybrid structure that the pre-fabricated FRP tubes serve as permanent formworks of fresh NAC and offer lateral confining pressure to enhance the strength and ductility of the NAC core [13-19]. In literature, some recent studies have investigated the behavior of RAC filled FRP tube [20-24]. For example, Gao et al. [21] compared the compressive behavior of CFRP tube and GFRP tube encased RAC cylinders. Ozbakkaloglu et al. [22] concluded that the RAC filled FRP tube with circular cross-sections showed higher compressive strength when compared with the specimens with square crosssections. Chen et al. [23] stated that the replacement ratio of RAs had a limited effect on the CFRP confinement effectiveness for RAC. Choudhury et al. [24] concluded that the initial stiffness of plain RAC-RCBA columns increased significantly with GFRP jacket confinement. Ardavan et al. [25] even found that CFRP strengthening increased the load capacity of the RAC beams and can be designed more load-affordable than the NAC beams.

However, synthetic GFRP and CFRP are expensive in their initial material price, nondegradable and non-recyclable. Against this background, recent researchers have used new confining materials to gain environmental and economic benefits. Polyester fiber, as one textile fiber, has advantages of large production, low price, degradability and appropriate mechanical properties [26-31]. Therefore, polyester FRP (PFRP) has been used to confine concrete columns. For example, Dai et al. [32] investigated the axial compressive behavior of PFRP tube encased NAC and was compared with aramid FRP (AFRP) tube confined NAC. This study showed that the PFRP confinement might not enhance the strength of the concrete as much as that of the AFRP but PFRP improved the ultimate strain of the NAC more pronouncedly and exhibited superior in cost performance. Ispir [33] stated that the PFRP confinement improved the strength and ultimate axial strain of confined NAC and had high deformation capacity which could be a good alternative in repairing or strengthening for seismic-resistant RC structures. Saleem et al. [34-35] concluded that PFRP encased NAC columns exhibited highly ductile behavior owing to the large rupture strain of the PFRP. Pimanmas et al. [36] demonstrated that the stress-strain behavior of PFRP tube encased NAC presented apparent softening stage and the compressive strength increased with more PFRP 
thickness. Huang et al. [37] investigated the effect of PFRP confinement ratios and concrete strength on compressive behavior of PFRP encased NAC. Huang et al. [38] also investigated the effects of slenderness and size of on the PFRP tube confined concrete cylinders.

Poly Vinyl chloride (PVC) materials were also extensively utilized in the construction industry as concrete moulds or pipes due to the high production, low price and stable service performance [39-41]. The apparent merits of PVC materials include: (1) excellent corrosion resistant, durability and mechanical stability, (2) smooth surface and good consistency with other materials, e.g., concrete, water and acids, (3) large ultimate strain (i.e., ductile), (4) high electrical insulation, (5) low diffusion for humidity, (6) low creep deformation, and (7) easy for machining, cutting, gluing for fabrication versatility. Research [42] showed that PVC tube did not lose strength significantly under the thermocycling tests. Nowack et al. [43] conducted tests on PVC tubes that were buried under soil for 60 years. They found that the PVC tubes did not deteriorate and was expected to serve for a further 50 years. Ranney et al. [44] found that PVC tubes could adequately resist the influence of chloridion, salts, freeze thawing and other chemical effects and maintain their long-term durability. Kurt [45] proposed PVC tube encased NAC for structural application and concluded that the PVC confined NAC performed like spiral steel confined concrete to afford effective ductility enhancement. Toutanji et al. [46-48] conducted experiments on mechanical properties and durability of GFRP-PVC tube encased NAC and found that the hybrid confinement enhanced the load carrying capacity and ductility of concrete and provided excellent durability even under high corrosive conditions. Wang et al. [49] stated that the thermal conductivity of PVC was only $0.45-0.6 \%$ of steel which would afford more stable condition without apparent change of temperature for concrete curing. Gupta et al. [50] investigated the PVC tube encased NAC under sea water for six months. The tested results indicated that no degradation in the strength and ductility of the confined NAC was observed and the PVC tube served as a safe jacket to protect the core concrete. Gathimba et al. [51] demonstrated that the confinement effectiveness of PVC confined NAC is dependent on the strength of concrete where the confinement ratio reduced with a higher strength of the concrete. Jiang et al. [52] explored the influence of slenderness ratio on CFRP-PVC tube encased NAC under uniaxial compression.

Based on the discussions above, it can be concluded that the cost-effective PFRP-PVC hybrid tube confinement has the potential to improve the mechanical properties of RAC-RCBA. Thus, in this study, PFRP-PVC tube encased RAC-RCBA (termed as PFRP-PVC-RACRCBA), for the first time, was proposed to improve the mechanical properties of RAC-RCBA. This PFRP-PVC-RAC-RCBA system was consisted of a PFRP (at the outer layer of the tube) and PVC (at the inner layer of the tube) hybrid tube and an RAC-RCBA infill as illustrated in Fig.1 (a). In this system, the inner PVC tube not only serves as the permanent formwork for the fresh RAC-RCBA but also serves as the permanent formwork for fabricating the outer PFRP tube using the typical hand lay-up process [59]. It should be pointed out here that for the typical hand lay-up process to make FRP tube, a mould (such as made of PVC or aluminum tube) is needed and then the resin-impregnated fiber fabrics are wrapped onto the mould. When the FRP tube is fully consolidated, it will be demoulded from the PVC or the aluminum tube. In the case of PFRP-PVC hybrid tube situation, the demoulding process of PFRP tube from the initial mould (e.g. a PVC tube) is not needed and in turn the construction time can be further reduced. Specifically, the objectives of this study included:

1) To obtain the optimal design mix ratio for RAC-RCBA cylinder by testing different replacement ratios of the RCBAs and different water-cement ratios;

2) To investigate the material properties of the PFRP and PVC composites with different thicknesses by flat coupon tensile tests;

3) To investigate the axial compressive behavior of PFRP-PVC-RAC-RCBA cylinders considering different column parameter effects: the number of PFRP layers $(3,6$ and 9layer), type of the PFRP confinement (i.e. in the configuration of PFRP tubes (see Fig1(b)) 
and strips (see Fig 1(b)) and the spacing distance of the PFRP strips (25 $\mathrm{mm}$ and $55 \mathrm{~mm}$ );

4) To develop stress-strain modes for PFRP-PVC-RAC-RCBA in axial compression by the regression analysis and iterative computations of the tested results.

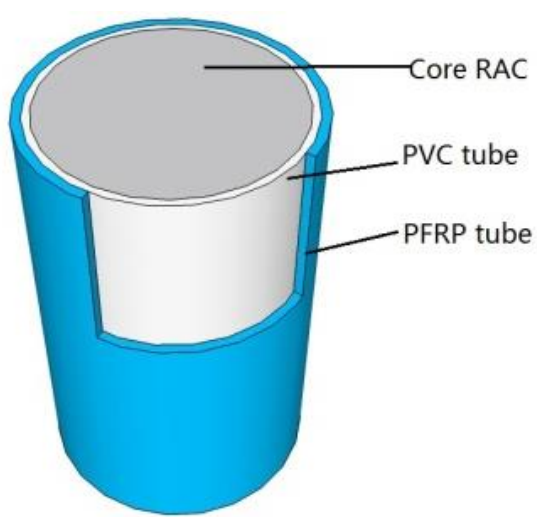

a) PFRP tube-PVC-RAC-RCBA cylinder

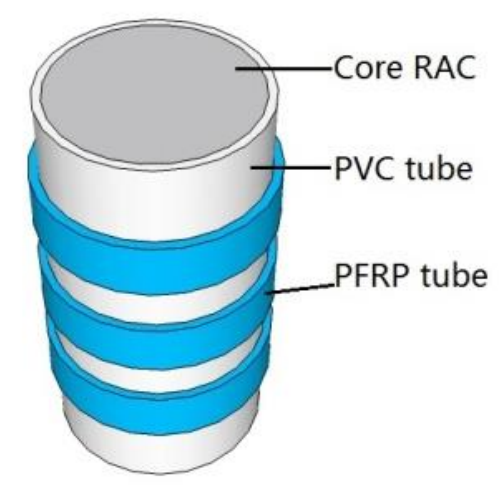

b) PFRP strip-PVC-RAC-RCBA cylinder Fig 1 PFRP-PVC-RAC-RCBA schematic diagram

Table 1 Physical property of RAs

\begin{tabular}{cccccc}
\hline $\begin{array}{c}\text { Partial size } \\
(\mathrm{mm})\end{array}$ & $\begin{array}{c}\text { Density } \\
\left(\mathrm{kg} / \mathrm{m}^{3}\right)\end{array}$ & $\begin{array}{c}\text { Porosity } \\
(\%)\end{array}$ & $\begin{array}{c}\text { Water absorption } \\
(\%)\end{array}$ & $\begin{array}{c}\text { Moisture content } \\
(\%)\end{array}$ & $\begin{array}{c}\text { Crushing index } \\
(\%)\end{array}$ \\
\hline $5 \sim 10$ & 1140 & 10 & 14.8 & 6.5 & 17.3 \\
\hline
\end{tabular}

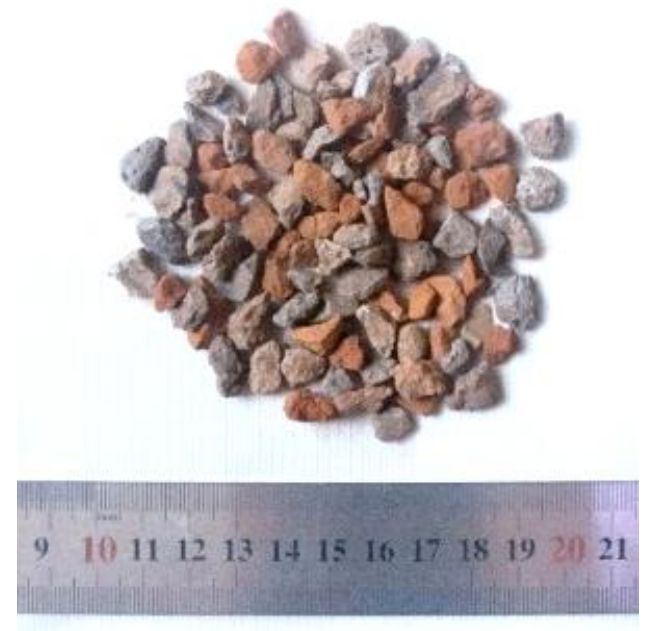

Fig.2 RAs used 
To evaluate the effects of replacement ratios of RAs and water-cement ratios on the compressive strength of RAC-RCBA, two groups of experimental works were conducted: Group A and Group B. The Group A consisted of three categories of RAC-RCBA cubes $\left(150 \times 150 \times 150 \mathrm{~mm}^{3}\right)$ corresponding to three different replacement ratios of RCBA (i.e., $50 \%$, $70 \%$ and $100 \%$ ). For each category of the specimens, six RAC-RCBA cubic specimens were constructed for the axial compression test. The details of the mix proportions of Group A are listed in Table 2. The Group B consisted of three categories of RAC-RCBA cubes $\left(150 \times 150 \times 150 \mathrm{~mm}^{3}\right)$ corresponding to three different water-cement ratios (i.e., $0.46,0.50$ and 0.56 ). For each category, six RAC-RCBA cubic specimens were also constructed for the axial compressive test. The details of the mix proportions of Group B are listed in Table 3. In Tables 2 and 3, $r$ indicates the replacement ratio of the RAs for the natural aggregates and $\omega / c$ indicates the water-cement ratio. In this study, vibratory mixing technology was applied to produce the RAC-RCBA by using a DT60 double-horizontal shafts mixer. The RACRCBA with vibratory mixing technology showed better in fluidity, load carrying capacity and durability [56-57]. The vibratory mixing technology combined the vibratory function into the traditional concrete stir to accelerate the stirring velocity, promoted the uniform distribution of the aggregates and accelerated the hydration process of the cement to enhance the bond between cement and aggregates. The crafts of vibratory mixing technology referred to a secondary stirring: the whole cement, aggregates and half of the water were poured into the mixer and rotated adequately for about $8-10 \mathrm{~s}$ in the first step of stirring, then the left half of the water was poured in and mixed for 30s for the second step of stirring. The fully mixed RAC-RCBA was poured into the moulds and compacted by vibrator. After pouring, all specimens were covered by soaking wet cloth and watered three times per day for 28 days.

Table 2 RAC-RCBA mix proportion of group A

\begin{tabular}{cccccccc}
\hline No. & $\omega / c$ & $\begin{array}{c}\text { Water } \\
\left(\mathrm{kg} / \mathrm{m}^{3}\right)\end{array}$ & $\begin{array}{c}\text { Cement } \\
\left(\mathrm{kg} / \mathrm{m}^{3}\right)\end{array}$ & $\begin{array}{c}\text { Fine aggregate } \\
\left(\mathrm{kg} / \mathrm{m}^{3}\right)\end{array}$ & $\begin{array}{c}\text { Coarse aggregate } \\
\left(\mathrm{kg} / \mathrm{m}^{3}\right)\end{array}$ & $\begin{array}{c}\text { RCBA } \\
\left(\mathrm{kg} / \mathrm{m}^{3}\right)\end{array}$ & $r$ \\
\hline 1 & 0.40 & 237.5 & 600.9 & 520.2 & 0 & 1041.4 & $100 \%$ \\
2 & 0.40 & 237.5 & 600.9 & 520.2 & 312.4 & 729.0 & $70 \%$ \\
3 & 0.40 & 237.5 & 600.9 & 520.2 & 520.7 & 520.7 & $50 \%$ \\
\hline
\end{tabular}

Table 3 RAC-RCBA mix proportion of group B

\begin{tabular}{cccccccc}
\hline No. & $\omega / c$ & $\begin{array}{c}\text { Water } \\
\left(\mathrm{kg} / \mathrm{m}^{3}\right)\end{array}$ & $\begin{array}{c}\text { Cement } \\
\left(\mathrm{kg} / \mathrm{m}^{3}\right)\end{array}$ & $\begin{array}{c}\text { Fine aggregate } \\
\left(\mathrm{kg} / \mathrm{m}^{3}\right)\end{array}$ & $\begin{array}{c}\text { Coarse aggregate } \\
\left(\mathrm{kg} / \mathrm{m}^{3}\right)\end{array}$ & $\begin{array}{c}\text { RCBA } \\
\left(\mathrm{kg} / \mathrm{m}^{3}\right)\end{array}$ & $r$ \\
\hline 1 & 0.46 & 292.3 & 635.4 & 571.0 & 310.1 & 731.0 & $70 \%$ \\
2 & 0.50 & 315.4 & 626.0 & 545.5 & 300.8 & 701.8 & $70 \%$ \\
3 & 0.56 & 362.1 & 650.0 & 545.5 & 301.0 & 702.1 & $70 \%$ \\
\hline
\end{tabular}

The cubic specimens at 7-day were tested under a DYE-2000 electro hydraulic compression machine to determine the compressive strength. The tested results of the RAC-RCBA cubes in Group A are illustrated in Fig. 3 and the coefficients of variation (COV) of the tested compressive strength obtained from six cubic specimens are also presented to demonstrate the degree of dispersion of tested results, which were calculated as the ratio of the standard deviation and the mean value of the strengths. It shows that the compressive strength of the RAC-RCBA with 70\% replacement ratio of RAs was the largest. The tested strengths of the RAC-RCBA specimens in the Group B are listed in Fig.4. It shows that for RAC with RAs replacement ratio of $70 \%$, the compressive strength showed a descending tendency with an increase of the water-cement ratios from 0.40 to 0.50 . The further increase of the watercement ratio from 0.50 to 0.56 resulted in a slight increase in the strength of the RAC. The slight increase in the strength for specimen with water/cement ratio of 0.56 might be attributed to the following two-folds: (1) the high porosity and water absorption of the RCBA limited the rates of hydration reaction of cement. With an increase of the water/cement ratio, the RCBA was saturated with water which weakened the hydration reaction of the cement and 
in turn increased the compressive strength slightly, (2) the old brick powder and old mortar adhered at surface of the RCBA had a negative effect on the hydration reaction of the cement. For specimen with a larger water/cement ratio of 0.56 , the old powder and old mortar limited the rates of hydration of the cement which resulted in a slight increase of the compressive strength. In addition, the RAC-RCBA with water-cement ratio of 0.40 and RAs replacement ratio of $70 \%$ had the highest compressive strength among all the categories in Group A and Group B.

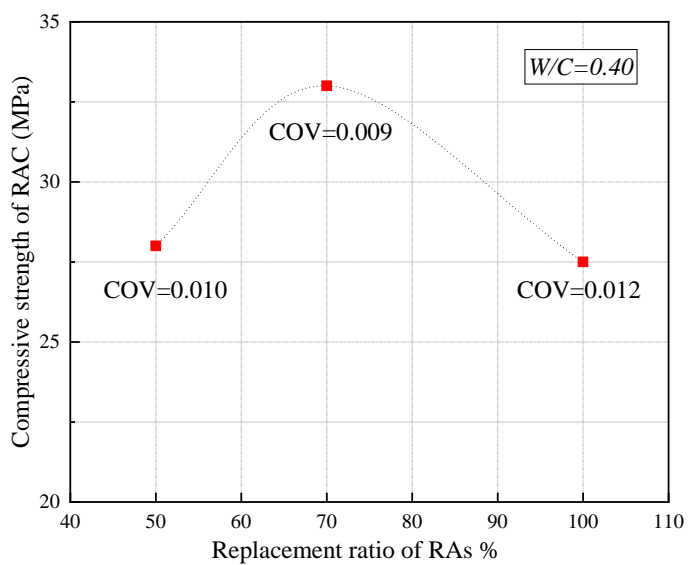

Fig.3 The influence of $r$ on compressive strength of RAC-RCBA

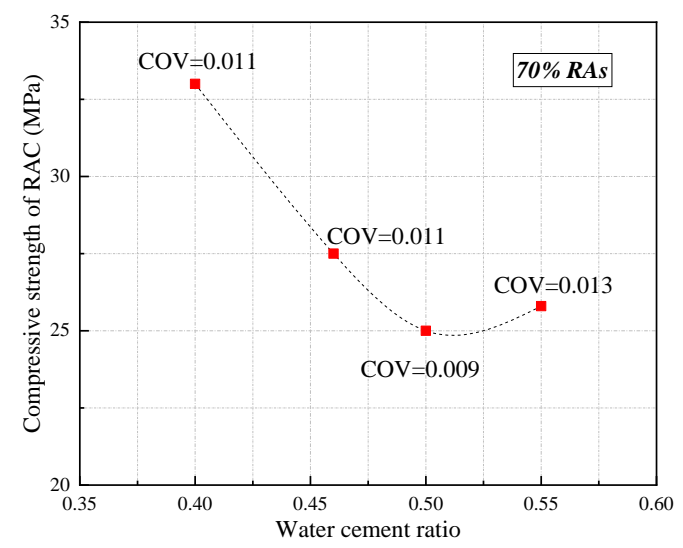

Fig.4 The influence of $w / c$ on compressive strength of RAC-RCBA

The failure modes of RAC-RCBA cubes are shown in Fig.5. In general, the experimental observations indicated that all the RAC-RCBA specimens in Group A and Group B presented a diagonal pyramid rupture face as illustrated in Fig 5(b), which was like that of the NAC counterpart. Compared with the NAC, most of the RCBAs in the RAC were crushed and broke under the compressive load, while most of the coarse NAs still maintained intact. This phenomenon can be interpreted by the much lower crushing index of NAs compared with that of the RAs.

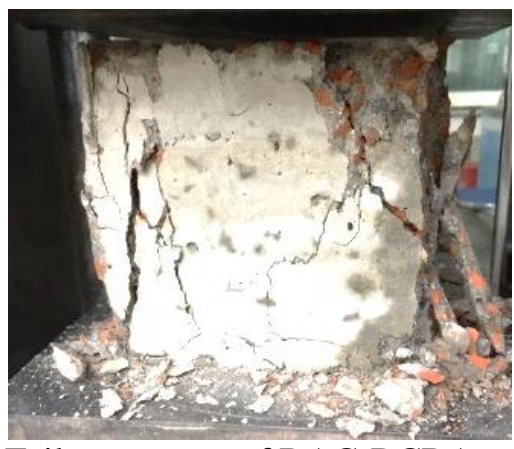

a) Failure pattern of RAC-RCBA cube

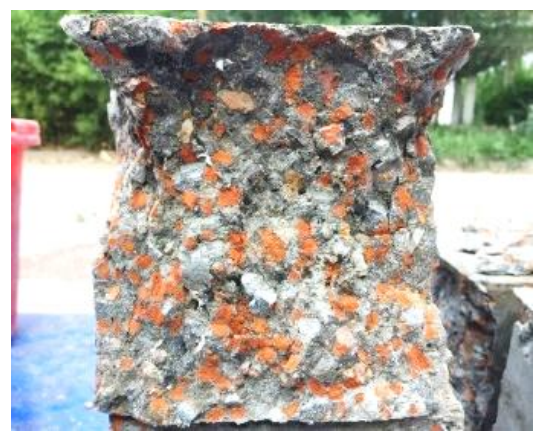

b) Rupture face of RAC-RCBA cube

Fig.5 Failure mode of RAC-RCBA cube

\subsection{Preparation of PFRP-PVC-RAC-RCBA}

\subsubsection{Test matrix}

To investigate the axial compressive behavior of PFRP-PVC-RAC-RCBA, 36 cylindrical specimens (i.e. 3 unconfined RAC-RCBA and 33 confined RAC-RCBA cylinders) were constructed and tested under axial compression. The tested variables included the number of PFRP layer (i.e. 3, 6, and 9-layer), the type of the PFRP confinement (i.e. in the configurations of tube (Fig. 1(a) and strips (Fig. 1(b))) and the spacing distance of the PFRP 
strips (i.e. $25 \mathrm{~mm}$ and $50 \mathrm{~mm}$ ). These specimens were classified into one category of unconfined RAC-RCBA, one category of PVC tube encased RAC-RCBA (i.e. PVC-RACRCBA), one category of PFRP tube encased RAC-RCBA (i.e. PFRP-RAC-RCBA), and nine categories of PFRP-PVC-RAC-RCBA (i.e. 3P-T, 3P-S25, 3P-S50, 6P-T, 6P-S25, 6P-S50, 9P$\mathrm{T}$, 9P-S25, and 9P-S50). For each category three identical specimen were tested. The details of all the specimens are listed in Table 4. For the PFRP tube-PVC-RAC-RCBA specimens, the letter $\mathrm{P}$ with a figure in the front was used to represent the specimens, i.e. 3P-T, 6P-T and 9P-T indicates 3-layer, 6-layer and 9-layer PFRP tube-PVC-RAC-RCBA specimens, respectively. For PFRP strip-PVC-RAC-RCBA specimens, the figure in front of the letter P denotes the number of layers of the PFRP strip and the figure behind the letter $\mathrm{S}$ denotes the spacing distances of the PFRP strip, e.g., the specimen code 3P-S25 denotes PFRP strip-PVCRAC-RCBA specimen with 3 layers of PFRP strips and spacing distance of $25 \mathrm{~mm}$. The diameter of the core RAC $D_{1}$ and the height of core RAC are $152 \mathrm{~mm}$ and $305 \mathrm{~mm}$, respectively. The external diameter of the PVC tube $D_{2}$ and the thickness of PVC tube is 160 $\mathrm{mm}$ and $4 \mathrm{~mm}$, respectively.

Table 4 Characteristics of tested cylindrical specimens

\begin{tabular}{|c|c|c|c|c|c|c|}
\hline No. & Specimen & $\begin{array}{c}D_{1} \text { of core RAC } \\
(\mathrm{mm})\end{array}$ & $\begin{array}{c}D_{2} \text { of PVC tube } \\
(\mathrm{mm})\end{array}$ & $\begin{array}{l}\text { Height } \\
(\mathrm{mm})\end{array}$ & $\begin{array}{l}\text { PFRP } \\
\text { layer }\end{array}$ & $\begin{array}{c}\text { PFRP confined } \\
\text { modes }\end{array}$ \\
\hline 1 & RAC-RCBA & 152 & - & 305 & - & - \\
\hline 2 & $\begin{array}{l}\text { PVC-RAC- } \\
\text { RCBA }\end{array}$ & 152 & 160 & 305 & - & - \\
\hline 3 & $\begin{array}{c}\text { PFRP-RAC- } \\
\text { RCBA }\end{array}$ & 152 & - & 305 & 6 & Tube \\
\hline 4 & $3 \mathrm{P}-\mathrm{T}$ & 152 & 160 & 305 & 3 & Tube \\
\hline 5 & $3 \mathrm{P}-\mathrm{S} 25$ & 152 & 160 & 305 & 3 & $\begin{array}{l}\text { spacing distance } \\
25 \mathrm{~mm}\end{array}$ \\
\hline 6 & 3P-S50 & 152 & 160 & 305 & 3 & $\begin{array}{l}\text { spacing distance } \\
50 \mathrm{~mm}\end{array}$ \\
\hline 7 & $6 \mathrm{P}-\mathrm{T}$ & 152 & 160 & 305 & 6 & Tube \\
\hline 8 & $6 \mathrm{P}-\mathrm{S} 25$ & 152 & 160 & 305 & 6 & $\begin{array}{l}\text { spacing distance } \\
25 \mathrm{~mm}\end{array}$ \\
\hline 9 & 6P-S50 & 152 & 160 & 305 & 6 & $\begin{array}{l}\text { spacing distance } \\
50 \mathrm{~mm}\end{array}$ \\
\hline 10 & 9PT & 152 & 160 & 305 & 9 & Tube \\
\hline 11 & 9P-S25 & 152 & 160 & 305 & 9 & $\begin{array}{c}\text { spacing distance } \\
25 \mathrm{~mm}\end{array}$ \\
\hline 12 & 9P-S50 & 152 & 160 & 305 & 9 & $\begin{array}{c}\text { spacing distance } \\
50 \mathrm{~mm}\end{array}$ \\
\hline
\end{tabular}

For all the confined RAC-RCBA, the concrete mix proportion of the RAC-RCBA followed the specimen with the highest compressive strength given in Section 2.1, namely, the RA replacement ratio of $70 \%$ and the water-cement ratio of 0.40 . The tested compressive strength of the RAC-RCBA at 28-day based on six identical specimens was $30.6 \mathrm{MPa}$, and the standard deviation was $0.45 \mathrm{MPa}$.

\subsubsection{PFRP materials}

The bidirectional polyester textile with an areal density of $250 \mathrm{~g} / \mathrm{m}^{2}$ and a thickness of 0.55 mm were used to fabricate the PFRP tubes. Fig.6 (a) shows the polyester textile used for the study. The textile was made by continuous polyester fibre filaments and these long fibres were oriented in the wrap and weft directions of the textile with an angle of $90^{\circ}$. According to ASTM D3039-M08 [54], flat coupon tensile tests were conducted on PFRP laminate to obtain the tensile strength, strain and modulus. The details of the PFRP laminates used for the flatcoupon tests are shown in Fig. 6. Aluminum bars of $50 \mathrm{~mm}$ in length and $25 \mathrm{~mm}$ in width were glued to the both ends of the PFRP laminates to avoid premature failure. The PFRP 
laminates with 1, 3, 6 and 9 layers of polyester fabric were tested under the tensile load by using the MTS CMT4204 universal testing machine.

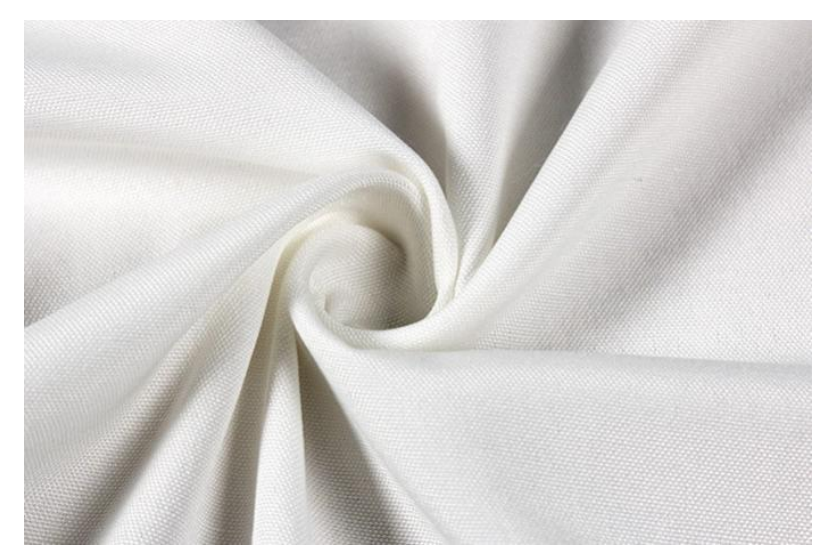

a)
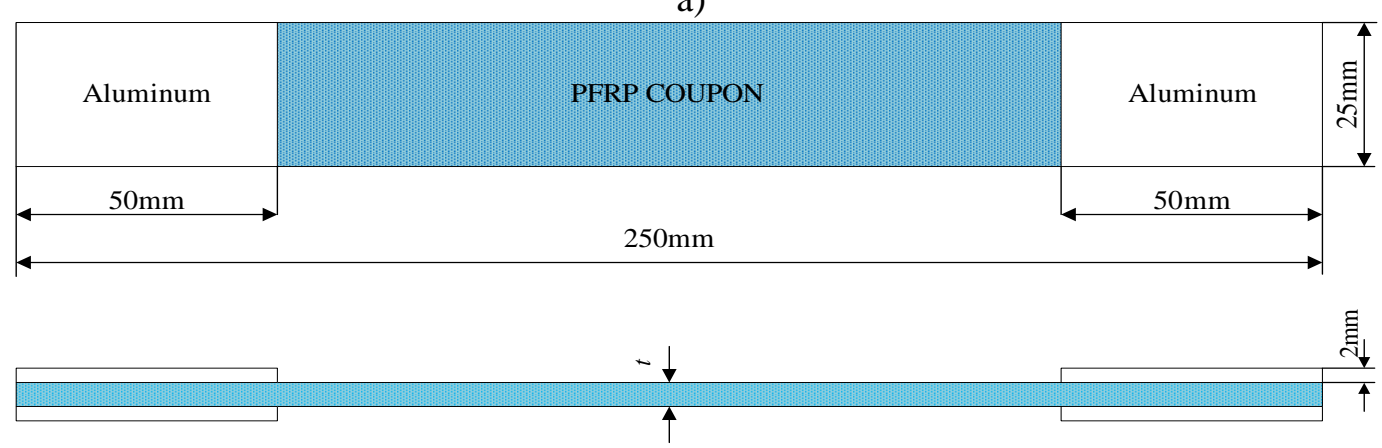

b) Dimension of the PFRP flat coupon

Fig 6 (a) The bidirectional polyester textile and (b) Dimension of the PFRP flat coupon

\subsubsection{PVC materials}

The 4 mm-thick PVC tubes were used for the PVC-RAC-RCBA, PFRP tube-PVC-RACRCBA and PFRP strip-PVC-RAC-RCBA specimens. Tensile tests were also carried out on the PVC flat coupon to determine their tensile properties. The size of the PVC coupon used for the tensile test is shown in Fig.7 according to the GB/T 8804.2-2003 [55], where $A=115 \mathrm{~mm}, B=25 \mathrm{~mm}, C=33 \mathrm{~mm}, D=6 \mathrm{~mm}, E=14 \mathrm{~mm}, F=25 \mathrm{~mm}, G=25 \mathrm{~mm}, H=80 \mathrm{~mm}$ and $I=4 \mathrm{~mm}$, respectively.

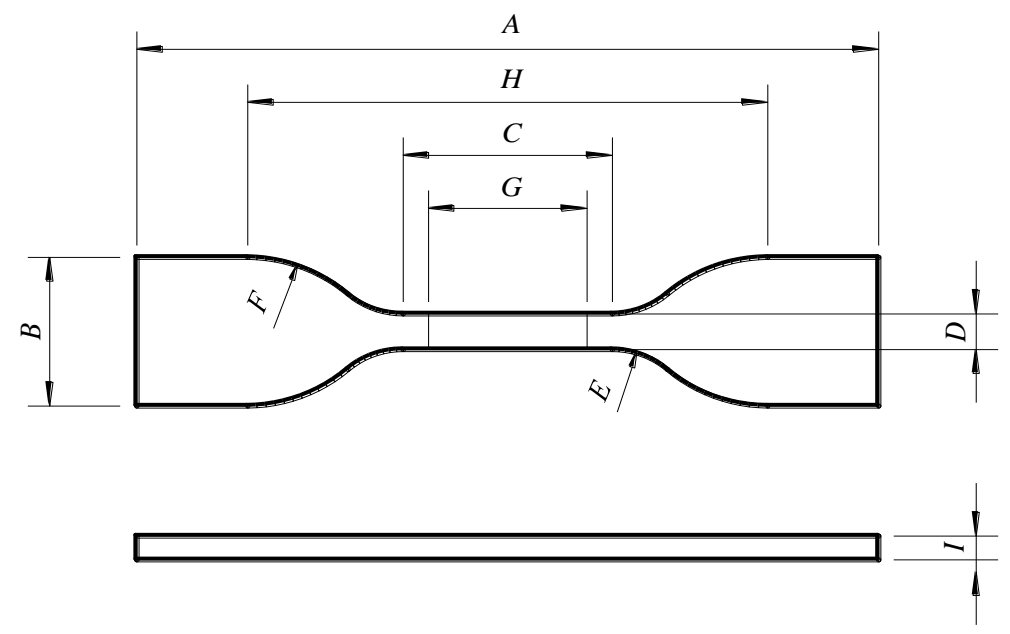

Fig. 7 The dimension of the tested PVC coupon

\subsubsection{Tensile behavior of PFRP, PVC and comparison with synthetic C/GFRP}


In this study, the tensile properties of PFRP and PVC were compared with the synthetic GFRP and CFRP composites which used for GFRP and CFRP tube confined RAC-RCBA [21]. The tensile stress-strain curves of PFRP, PVC and GFRP and CFRP obtained from flatcoupon tensile tests are shown in Fig. 8, 9 and 10. The PFRP composites showed a nonlinear response until the peak stress and then the specimens failed suddenly, which was independent of the thickness of the PFRP laminate. The PVC showed an initial linear response to the level of the peak stress and followed by a stress plateau with significant enhancement in the tensile strain, indicating a ductile behavior. For both the GFRP and CFRP composites, their curves exhibited an approximate elastic response until the peak stress. For both the GFRP and CFRP composites, their tensile stress-strain curves exhibited an approximate elastic response until the peak stress. The damage of the CFRP and GFRP composites in tension was a progressive and brittle failure process. More details on the progressive degradation failure process of FRP composites and how to model the progress numerically were introduced by Riccio et al. [6870]. The tensile properties of PFRP, PVC, GFRP and CFRP composites are listed in Table 5. The tensile strength, ultimate strain and elastic modulus were the mean value of the tested results from the flat-coupon tensile tests and the standard deviations are given to present the dispersion of the tested results. The tensile modulus and tensile strength of GFRP and CFRP were significantly larger than those of PFRP and the PVC. However, the tensile strain at break of PVC and PFRP were much larger than those of the CFRP and GFRP, e.g. the tensile strain of PVC was 10 times that of the GFRP. In addition, an increase in the thickness of the PFRP composite resulted in an increase in tensile strength and modulus, but a slight reduction in the tensile strain. The polymer resin used for PFRP, CFRP and GFRP were the same, i.e. epoxy matrix with a commercial name of JN-C3P adhesive obtained from GOODBOND construction technic co., Ltd in China. The tensile strength, compressive strength, flexural strength and tensile elastic modulus of the JN-C3P resin provided by the supplier are $55 \mathrm{MPa}$, $32183.6 \mathrm{MPa}, 75 \mathrm{MPa}$ and 3.5 $\mathrm{GPa}$, respectively.

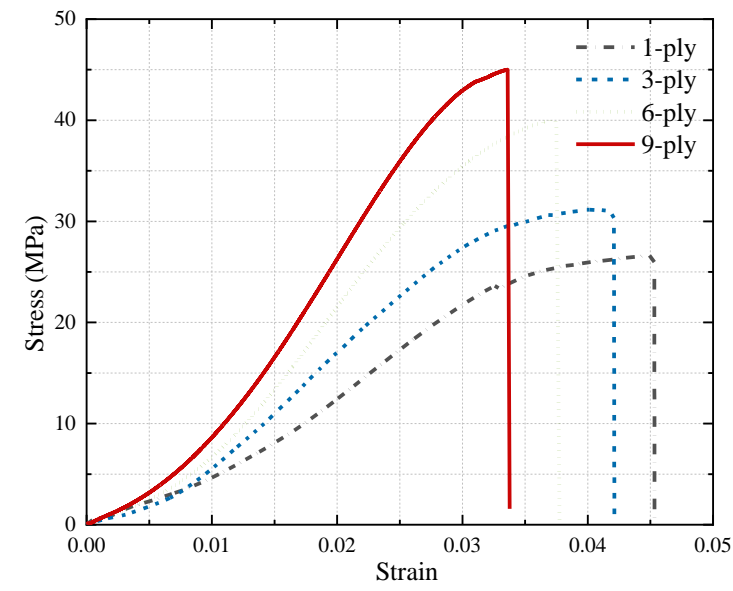

Fig 8 Tensile stress-strain behavior of PFRP

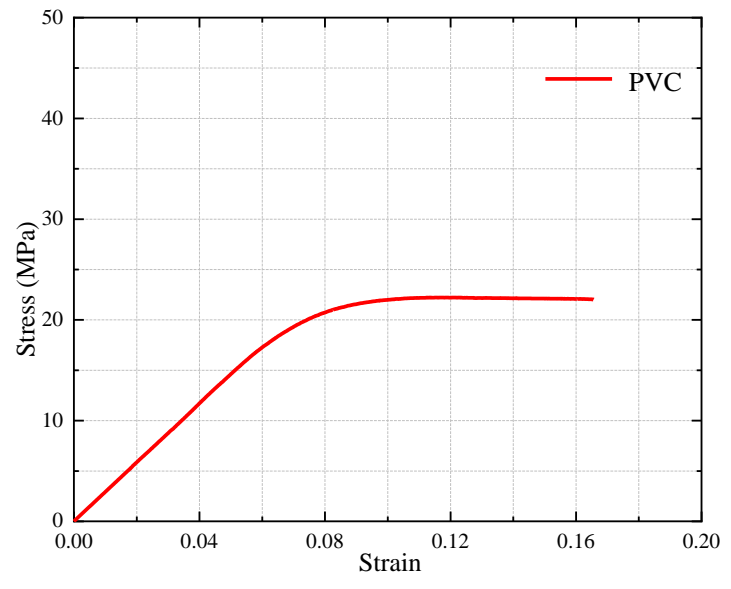

Fig. 9 Tensile stress-strain behavior of PVC 


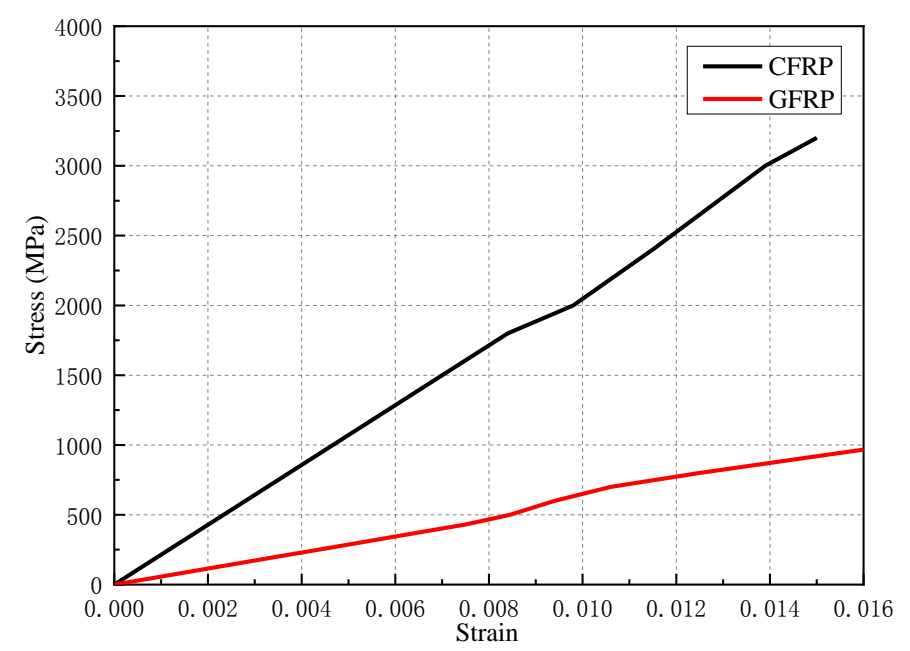

Fig. 10 Tensile stress-strain behavior of CFRP and GFRP [21]

Table 5 Tensile properties and standard deviation (SD) of PFRP, PVC, GFRP and CFRP composites

\begin{tabular}{|c|c|c|c|c|c|c|c|}
\hline Group & $\begin{array}{l}\text { Thickness of } \\
\text { FRP (mm) }\end{array}$ & $\begin{array}{c}\text { Tensile } \\
\text { strength } \\
(\mathrm{MPa})\end{array}$ & $\begin{array}{c}\mathrm{SD} \\
(\mathrm{MPa})\end{array}$ & $\begin{array}{l}\text { Ultimate } \\
\text { strain }(\%)\end{array}$ & $\begin{array}{c}\mathrm{SD} \\
(\mathrm{MPa})\end{array}$ & $\begin{array}{c}\text { Elastic } \\
\text { Modulus } \\
(\mathrm{GPa})\end{array}$ & $\begin{array}{c}\mathrm{SD} \\
(\mathrm{MPa}) \\
\end{array}$ \\
\hline PFRP1 & 0.66 & 27.1 & 1.5 & 4.4 & 0.4 & 0.9 & 0.08 \\
\hline PFRP3 & 1.72 & 31.1 & 1.3 & 4.1 & 0.2 & 1.2 & 0.10 \\
\hline PFRP6 & 3.18 & 41.7 & 1.7 & 3.8 & 0.1 & 1.6 & 0.12 \\
\hline PFRP9 & 5.12 & 45.1 & 1.4 & 3.4 & 0.2 & 2.0 & 0.13 \\
\hline PVC & 4.00 & 22.5 & 0.7 & 16.0 & 0.1 & 0.3 & 0.03 \\
\hline GFRP & 2.62 & 967.0 & - & 1.6 & - & 60.8 & - \\
\hline CFRP & 0.96 & 3200.0 & - & 1.5 & - & 213.0 & - \\
\hline
\end{tabular}

\subsection{Fabrication of confined specimens}

The PVC tube and the polyester fabrics were firstly cut into designated size based on the dimension of the specimens listed in Table 4. The PFRP tubes and PFRP-PVC tubes were produced by a hand lay-up process as illustrated in Fig. 11[38]. The fabrication of the PFRP tube by hand lay-up process mainly included the following steps: 1). Cut polyester textile to designated size based on the diameter of the polymer FRP tube used, 2) surface preparation of hollow PVC tube mould with a thin release plastic film for easy demould, 3) preparation of epoxy mixture, 4) wrapped epoxy-impregnated polyester fabric to the PVC mould, 4) curing of the PFRP tubes, and 5) demoulding PFRP tube from the PVC mould. For the PFRP-PVC tube with PFRP tube or PFRP strips, the process was similar. The PVC tube was used as the mould directly and then the epoxy-impregnated polyester fabrics were wrapped into the PVC tube to make the PFRP-PVC tube. For the fabrication of PFRP strip-PVC tube, the position of polyester fabric strip was initially oriented and labelled on the PVC tube. The air bubble and additional epoxy resin were squeezed out when the PFRP sheets were rolled onto the PVC tube. For all the confined RAC-RCBA specimens, vibratory mixing technology was used as described in Section 2.1.2. To avoid the premature failure of the confined specimens, two narrow PFRP strips were wrapped on both ends of the PFRP-RAC-RCBA, PVC-RAC-RCBA and the PFRP -PVC-RAC-RCBA specimens.

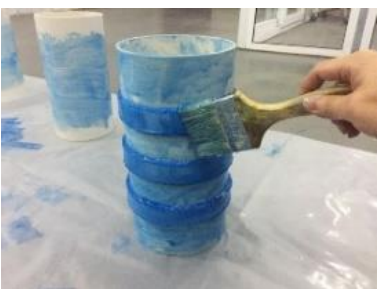

a) PFRP strip-PVC tube

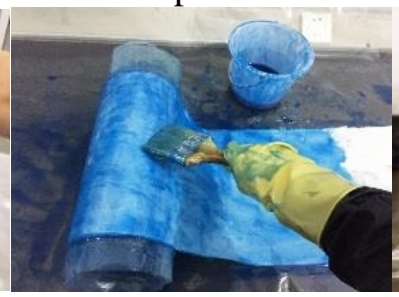

b) PFRP tube

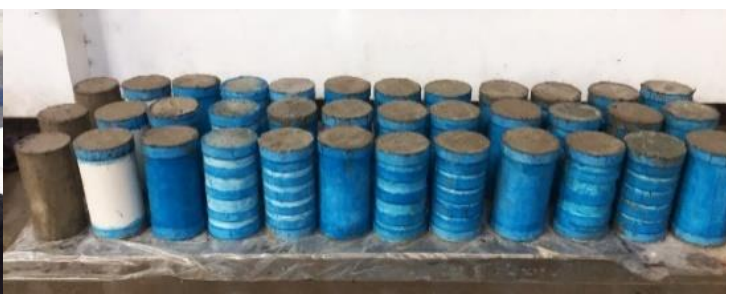

c) All the confined specimens

Fig.11 Fabrication of the specimens 


\subsection{Test instrumentation and procedures}

The MTS SANS YAW6506 electro-hydraulic testing machine was used for the uni-axial compression tests (Fig. 12(a)). The loading process was executed by a displacement-control. As illustrated in Fig. 12(b)-(c), four axial strain gauges (i.e., SG1, SG2, SG3, SG4) and four lateral strain gauges (i.e., SG5, SG6, SG7, SG8) were installed on the mid-height of the cylinders for measurement of axial strain and hoop strain, and two extra axial strain gauges were installed on each end of PFRP tube-PVC-RAC-RCBA cylinders (i.e., SG9 and SG11 at the top of PFRP tube-PVC-RAC-RCBA specimens, SG10 and SG12 at the bottom of PFRP tube-PVC-RAC-RCBA specimens), respectively. The applied load and vertical deformation were recorded by MTS system of the compression testing machine. The axial strain, lateral strain, applied load and vertical deformation were measured and recorded simultaneously. 356

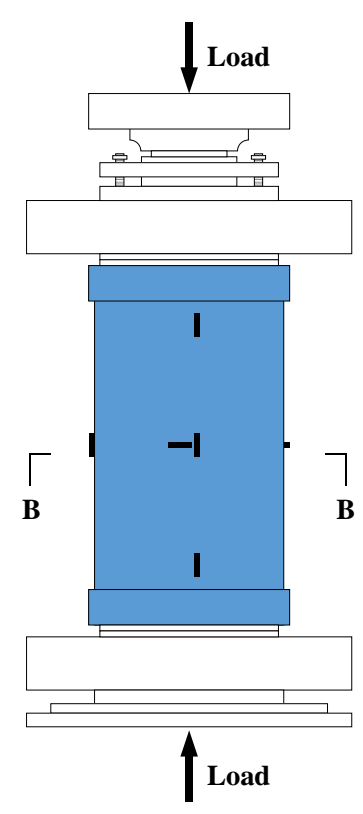

a) MTS pressure testing machine

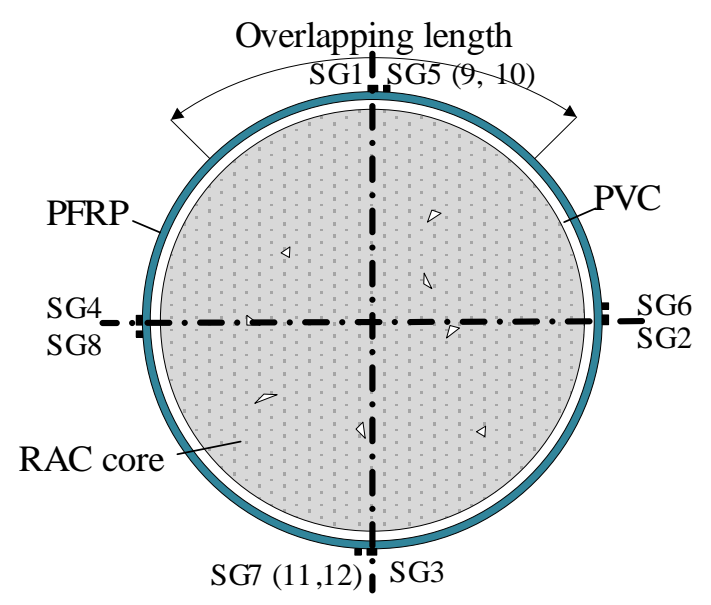

b) Placement of strain gauges

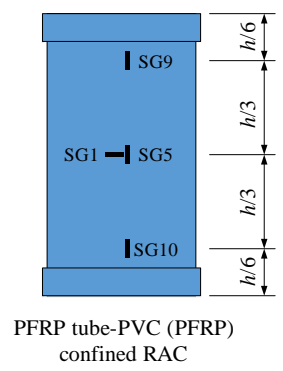

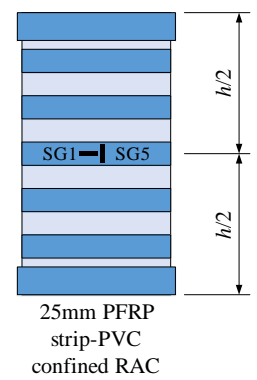
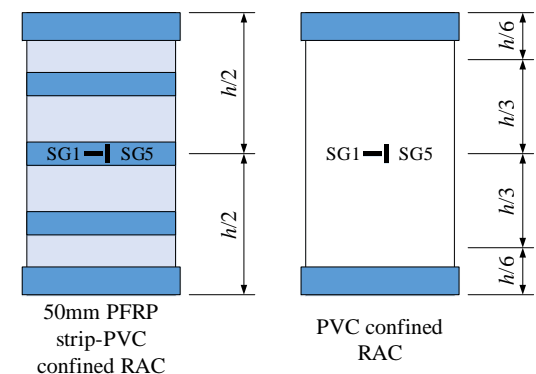

PVC confined RAC

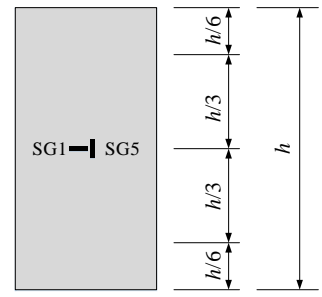

uconfined RAC

c) Elevation of strain gauges on specimens

Fig.12 Test instrumentation

\section{Results and discussion}

\subsection{Failure modes}

For the unconfined RAC-RCBA cylinders, the cracks emerged around the surface of the cylinders after the applied load was up to $40 \%$ of its peak strength. The load decreased rapidly after reached its peak strength $f_{\text {co }}$ and the cylinders finally failed in a brittle manner with several major vertical cracks (as illustrated in Fig 13(a)). For PVC-RAC-RCBA (i.e. only with PVC tube confinement) specimens, the specimens failed with several longitudinal cracks at the PVC tube and the tube were bulged apparently as illustrated in Fig. 13(b). The obvious bulge of the PVC tube might be caused by the significant lateral expansion of the inner RAC- 
RCBA core due to the confinement provided by the PVC tube, which possessed a significantly large tensile strain (Table 5). For the PFRP-RAC-RCBA, only a single longitudinal crack appeared along the PFRP tube, no obvious bulging of the tube was observed, as shown in Fig.13(c). This phenomenon in the different level of bulge of the PFRP and PVC tube might be interpreted by the less ultimate tensile strain of the PFRP. For PFRP tube-PVC-RAC-RCBA specimens with different thicknesses of the PFRP tube, their failure modes were similar and had a single longitudinal crack in the PFRP-PVC tubes. No debonding between PFRP and PVC tubes was observed. In addition, apparent bulging of the PFRP-PVC tubes was observed, as illustrated in Fig. 13(d), (e) and (f). Thus, the increase in the PFRP thickness did not change the general failure mode of the PFRP-PVC-RAC-RCBA. For PFRP strip-PVC-RAC-RCBA specimens, the failure modes were different from the PFRP tube-PVC-RAC-RCBA. The PFRP-strip-PVC-RAC-RCBA specimens had circumferential cracks at the PVC tubes and the longitudinal cracks did not go through the whole height of the PFPR-strip-PVC tubes, as shown from Fig 13(g)-(1). The appearance of the hoop rupture at the PVC tubes attributed to the local strengthening effect of the PFRP strips on the PVC tubes. As can be further observed, the increase of the thickness of the PFRP strips and the change of the spacing of the PFRP strips did not change the failure modes of the PFRP strip-PVC-RACRCBA.

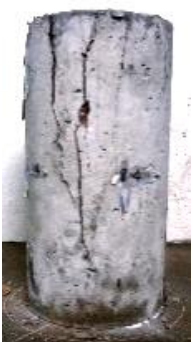

a) RAC-

RCBA

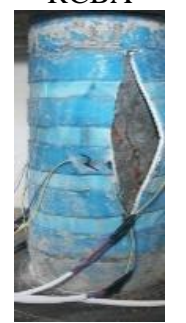

g) 3P-S25

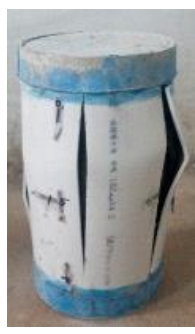

b) PVC-RACRCBA

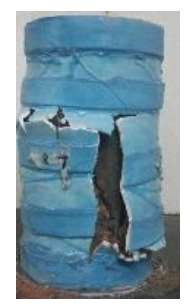

h) $3 \mathrm{P}-\mathrm{S} 50$

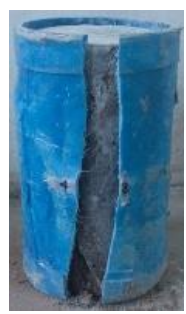

c) PFRP-RACRCBA

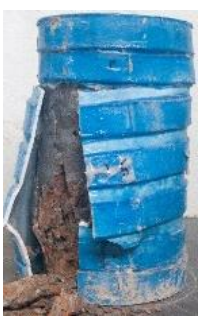

i) $6 \mathrm{P}-\mathrm{S} 25$

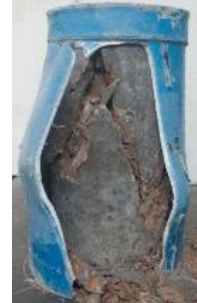

d) 3P-T

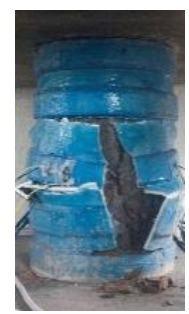

j) $6 \mathrm{P}-\mathrm{S} 50$

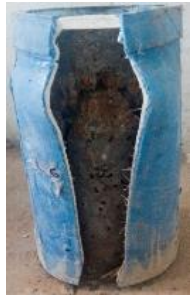

e) 6P-T

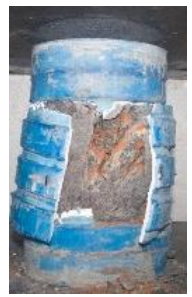

k) $9 \mathrm{P}-\mathrm{S} 25$

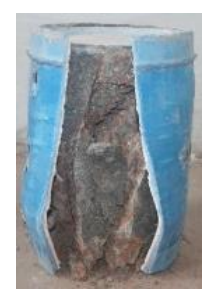

f) $9 P-T$

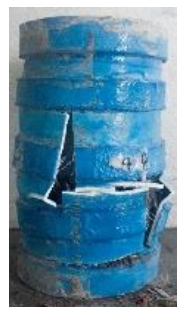

1) $9 \mathrm{P}-\mathrm{S} 50$

Fig.13 Failure modes of different confined RAC-RCBA specimens

\subsection{Axial stress-strain behavior}

\section{6}

\subsubsection{The typical compressive stress-strain curves of PFRP-PVC-RAC-RCBA}

The typical compressive stress-strain curves of unconfined RAC-RCBA, PVC-RAC-RCBA, 6-layer PFRP-RAC-RCBA, 6-layer PFRP tube-PVC-RAC-RCBA, 6-layer $25 \mathrm{~mm}$ and $50 \mathrm{~mm}$ PFRP strip-PVC-RAC-RCBA specimens are illustrated in Fig 14. One representative compressive stress-strain curve obtained from one of the three specimens for each type of FRP confined RAC-RCBA specimens was used to plot the figure. For PVC-RAC-RCBA and PFRP-RAC-RCBA specimens, their curves can be characterized by two distinct stages: the first linear elastic response to the peak stress and followed by a nonlinear descending stage. No obvious transition zone between the first linear stage and the second non-linear stages can be found. In general, the stress-strain curve of PFRP-PVC-RAC-RCBA can be divided into three zones: the first linear elastic ascending stage close to the peak stress, the second distinct short non-linear ascending zone until the peak stress and the third non-linear descending stage after the peak stress. Fig 15 gives a schematic view of the compressive stress-axial strain curve for PFRP-PVC-RAC-RCBA specimens, which can be represented by two key points: 
the transitional point (TP) corresponds to the peak stress point (i.e., peak stress $f_{\mathrm{ct}}$ and corresponding peak strain $\varepsilon_{\mathrm{ct}}$ point) and the ultimate point (UP) corresponds to the end of the curves at the ultimate state (i.e., ultimate strain $\varepsilon_{\mathrm{cu}}$ and corresponding ultimate stress $f_{\mathrm{cu}}$ ). Unlike the traditional CFRP and GFRP confined RAC (e.g. when the CFRP and GFRP had a thickness of 4 and 6 layers in Ref. [21], where 4-layer and 6-layer GFRP-RAC and CFRPRAC showed an ascending branch in the second stage of the compressive stress-strain curves) which showed a typical bilinear response with a linear and ascending stage after the transition zone, all the PFRP-RAC-RCBA, PVC-RAC-RCBA, and PFRP-PVC-RAC-RCBA showed the descending stages at the second stage. In the other words, the ultimate strain does not happen at the peak stress point but develops until the failure of specimens due to the ductility of materials [38]. Therefore, the PFRP-RAC-RCBA, PVC-RAC-RCBA and PFRP-PVCRAC-RCBA specimens can be defined as weakly-confined specimens, although enhancement

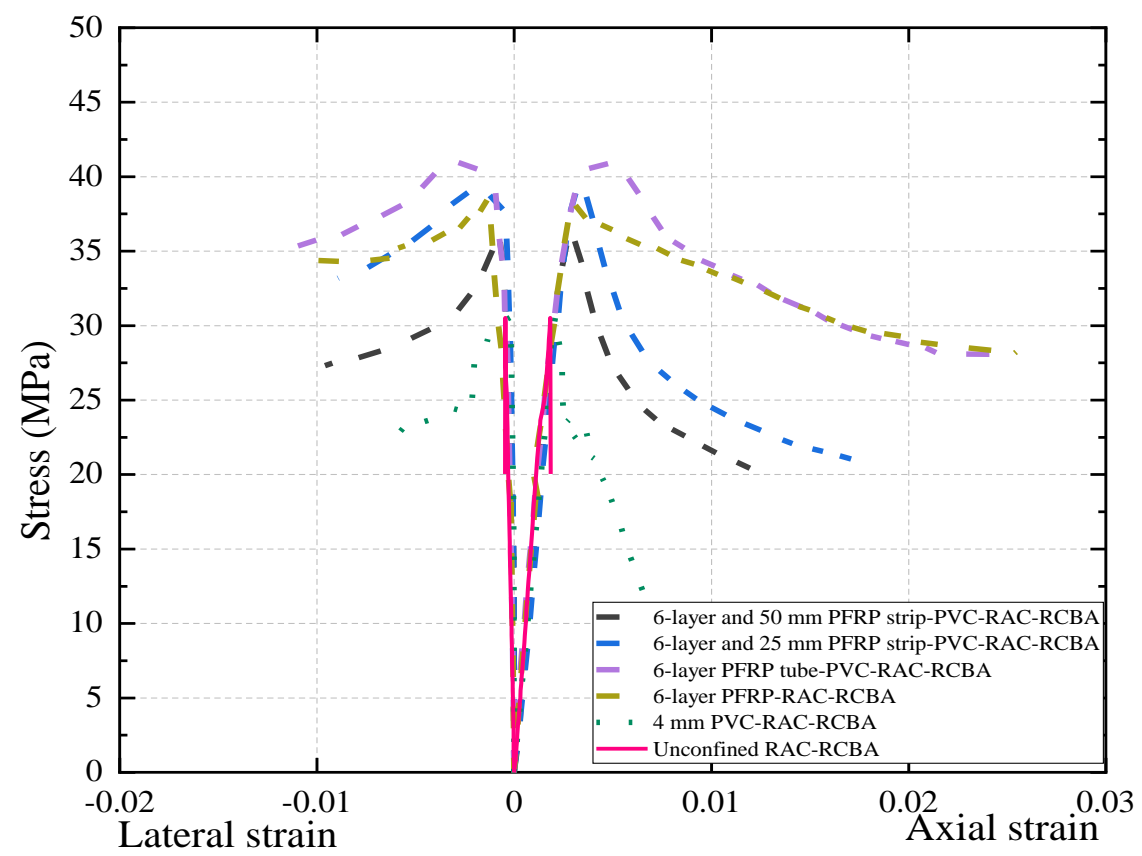

Fig.14 Stress-strain curves of different confinement modes

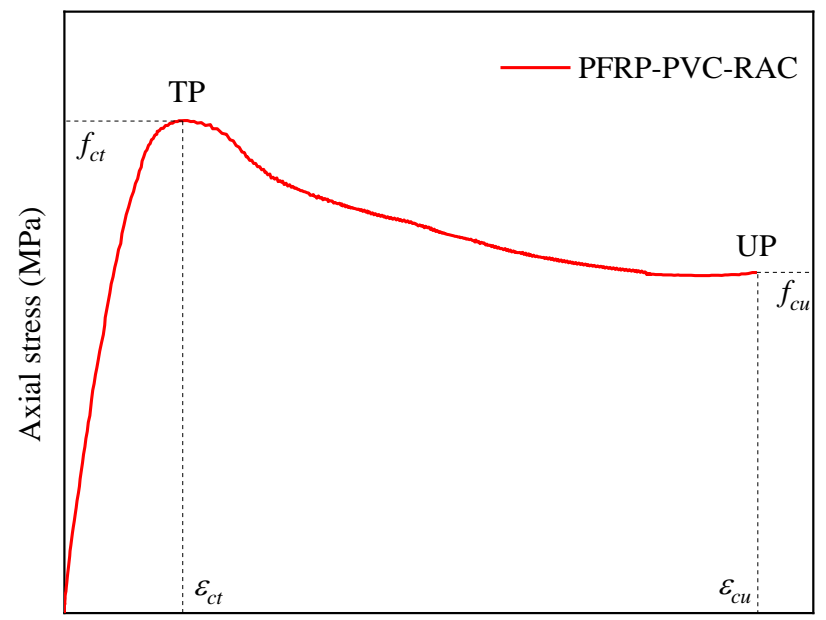

Axial strain

Fig.15 Typical axial compressive stress-strain curves of PFRP tube-PVC-RAC-RCBA and PFRP strip-PVC-RACRCBA

\subsubsection{The influence of confinement types on compressive stress-strain behavior}


The overall patterns of the stress-strain behaviors of PFRP-RAC-RCBA, 6-layer PFRP tubePVC-RAC-RCBA and 6-layer PFRP strip-PVC-RAC-RCBA with spacing distances of 25 and $50 \mathrm{~mm}$ illustrated in Fig. 14 are similar, which consisted of three stages: the initial elastic linear ascending stage, the second nonlinear ascending stage and the final descending stage. The PVC-RAC-RCBA specimens showed steeper descending stage and less peak stress than PFRP-RAC-RCBA, PFRP strip-PVC-RAC-RCBA and PFRP tube-PVC-RAC-RCBA specimens, but less slope of descending stage than that of the plain RAC-RCBA. The stressstrain curve of 6-layer PFPR-RAC-RCBA exhibited a sharper turning point from the peak stress point to the descending stage and larger slope of the descending stage than those of 6layer PFRP tube-PVC-RAC-RCBA specimens. While the ultimate strains at UP point of 6layer PFPR-RAC-RCBA were like those of 6-layer PFRP tube-PVC-RAC-RCBA but the peak stress at TP point of 6-layer PFPR-RAC-RCBA was lower than that of 6-layer PFRP tube-PVC-RAC-RCBA and was close to that of 6-layer and $25 \mathrm{~mm}$ spacing distance PFRP strip-PVC-RAC-RCBA. The stress-strain curves of 6-layer PFRP strip-PVC-RAC-RCBA presented obviously more steep descending stage than that of 6-layer PFRP tube-PVC-RACRCBA, and the ultimate axial strain and peak stress of 6-layer PFRP strip-PVC-RAC-RCBA were less than those of 6-layer PFRP tube-PVC-RAC-RCBA.

\subsubsection{The influence of PFRP thickness on stress-strain behavior}

According to Fig. 16(a), the stress-strain behavior of PFRP tube-PVC-RAC-RCBA showed a little steeper trend at the second ascending stages with a decrease of PFRP thickness and more placid descending stages with an increase of PFRP thickness, and the TP points performed gentler transition with an increase of PFRP thickness. The stress-strain curves of PFRP stripPVC-RAC-RCBA of the same spacing distance of PFRP strip in Fig. 16 (b) and (c) exhibited similar trend to those of PFRP tube-PVC-RAC-RCBA that the initial ascending stages were coincided with that of plain RAC-RCBA, the slopes of the second ascending stages became lower and the descending stages turn more placid with an increase of PFRP thickness. The ultimate strains at UP point and peak stress at TP point were higher for all PFRP-PVC-RACRCBA specimens with an increase of PFRP thickness.

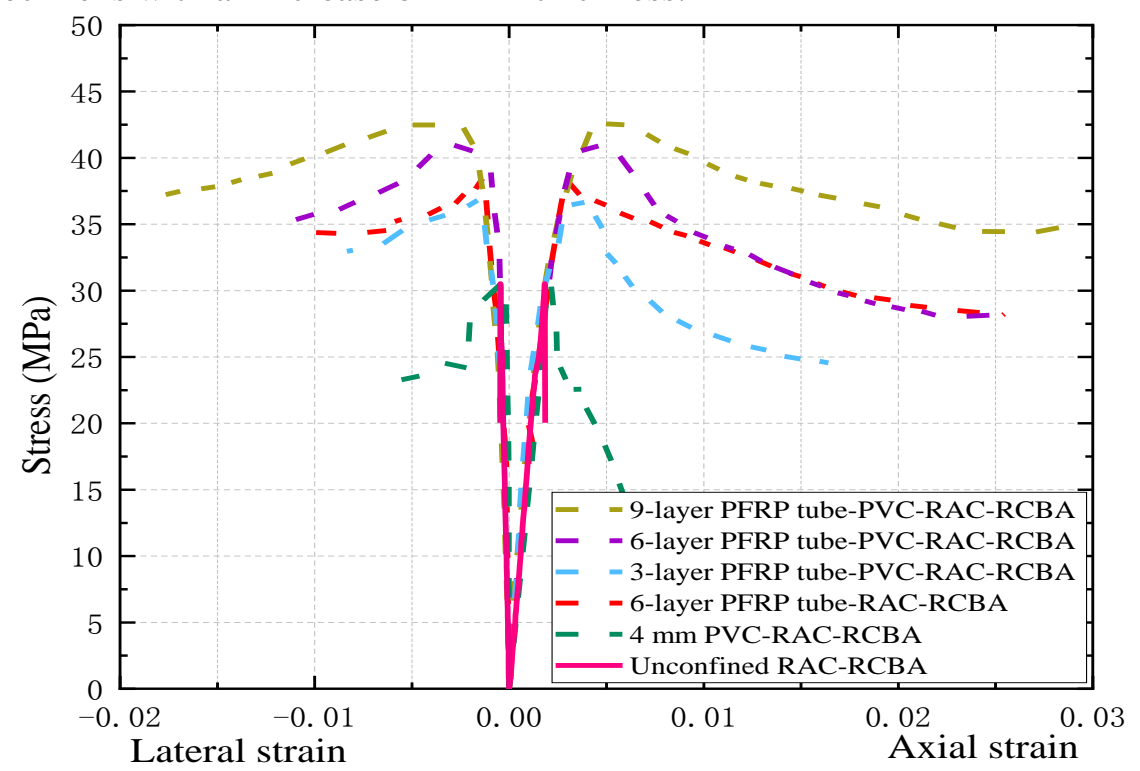

a) PFRP tube 


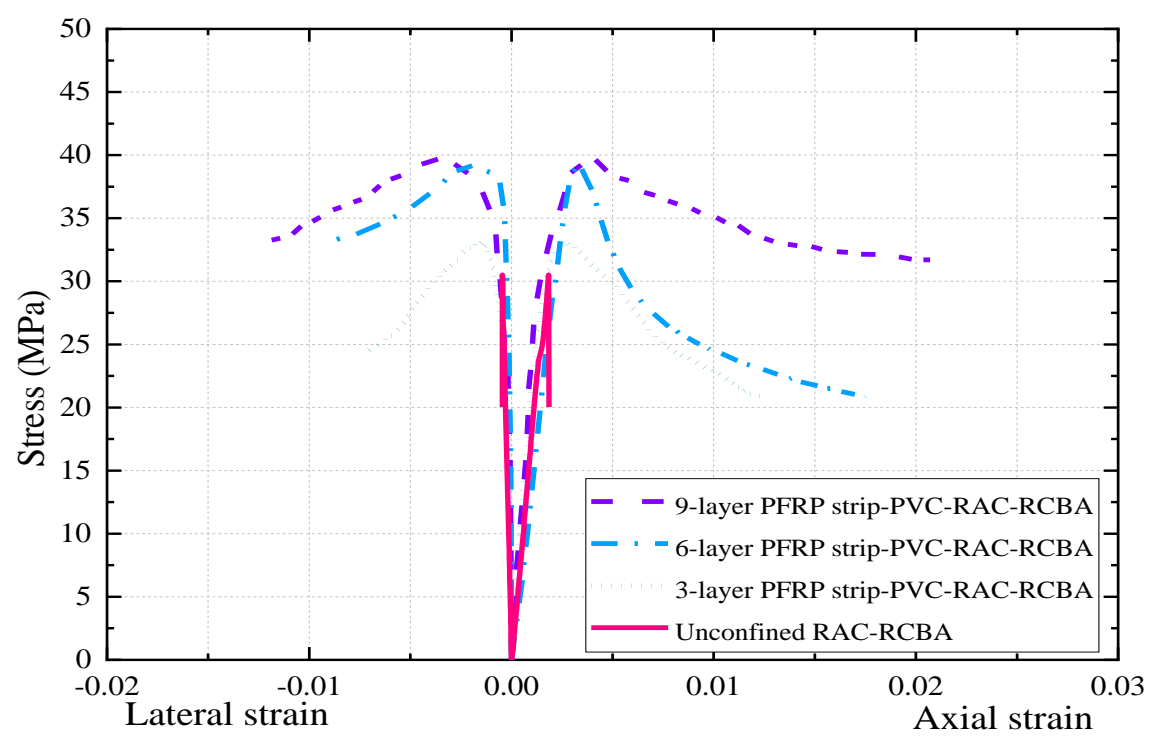

b) PFRP strip with spacing of $25 \mathrm{~mm}$

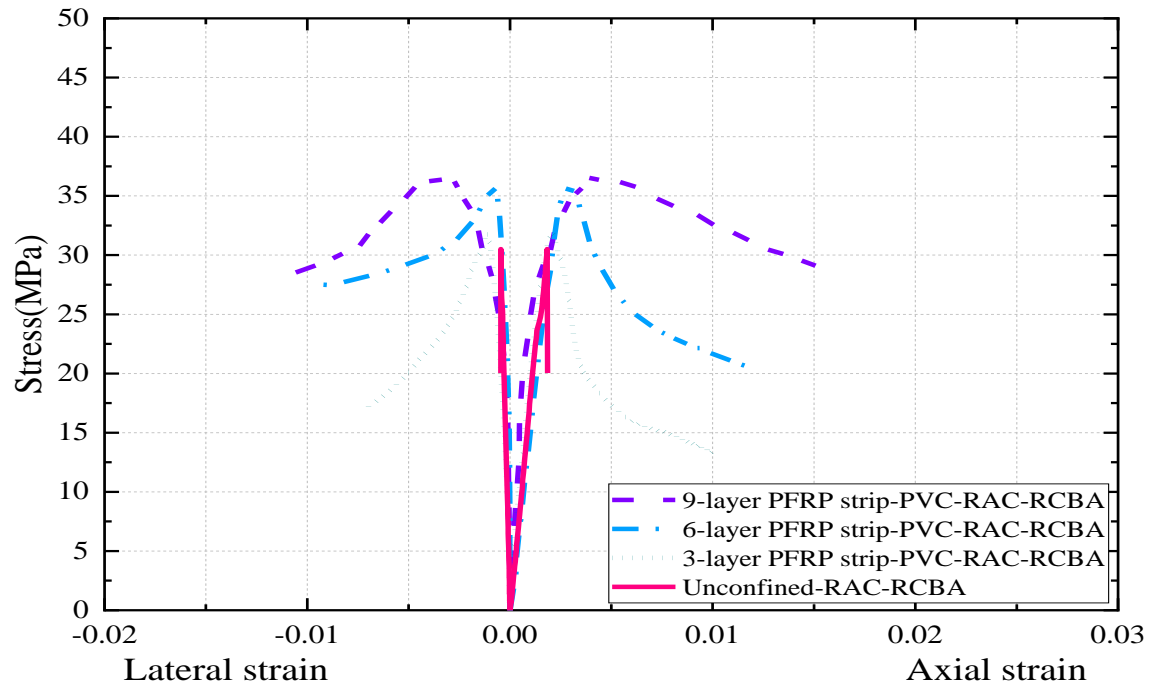

c) PFRP strip with spacing of $50 \mathrm{~mm}$

Fig.16 Stress-strain curves of different PFRP layers-PVC confined RAC-RCBA cylinders

\subsubsection{The influence of spacing distance of PFRP strip on stress-strain behavior}

445 The stress-strain curves in Fig. 17 present similar trend with different spacing distances of PFRP strip to the typical stress-strain behavior in Fig. 15. The ascending stages of 3-layer and 6-layer PFRP strip-PVC-RAC-RCBA groups exhibited the similar slope with different spacing distance of PFRP strip while the slopes of the descending stages became lower with a decrease of spacing distance of PFRP strip. For 9-layer PFRP strip-PVC-RAC-RCBA group, the slopes of the second ascending stages increased obviously with a decrease of spacing distance of PFRP strip, besides the descending stages showed more placid with a decrease of spacing distance of PFRP strip. For all PFRP strip-PVC-RAC-RCBA specimens, the ultimate strains at UP point and peak stress at TP point increased with a decrease of spacing distance of PFRP strip. 


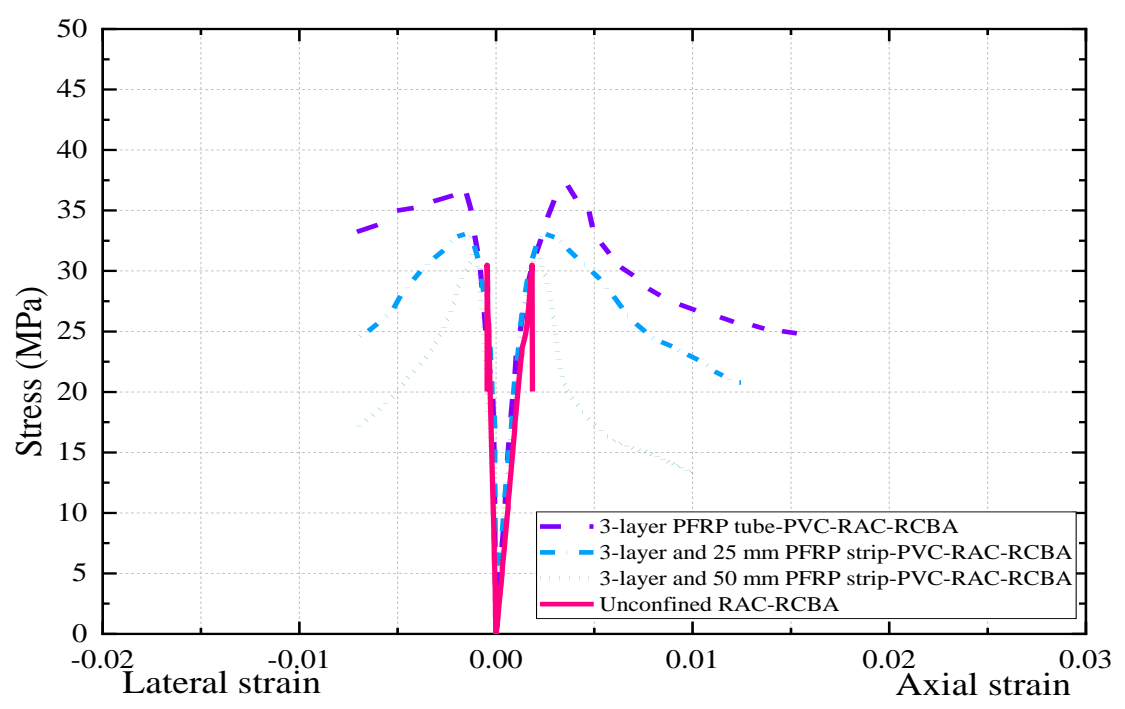

a) 3-layer PFRP

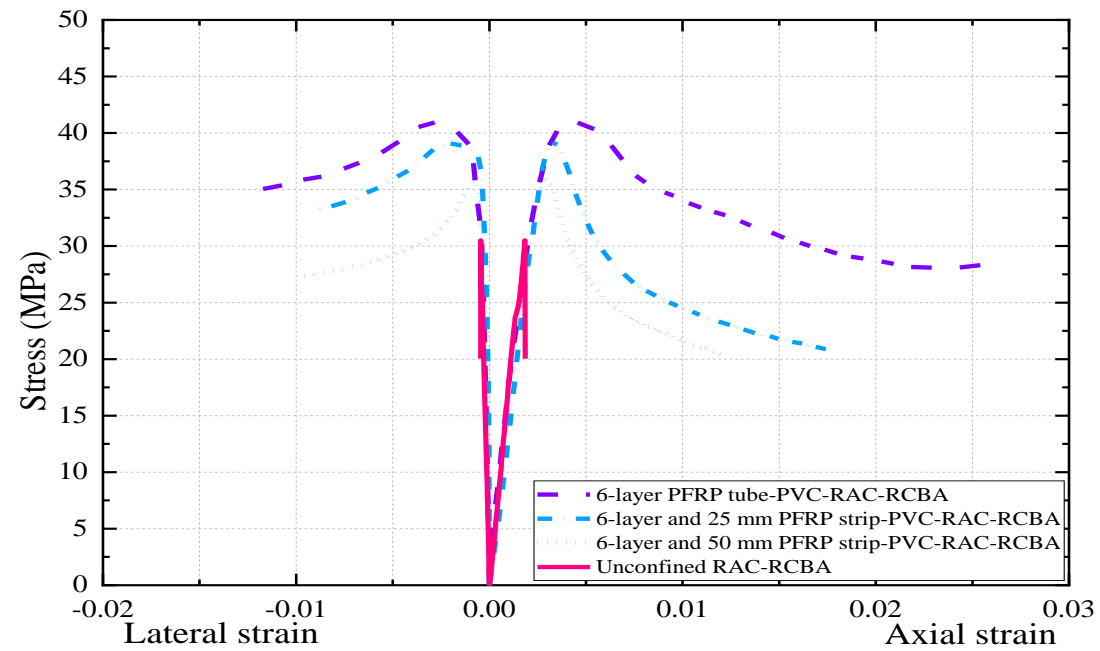

b) 6-layer PFRP

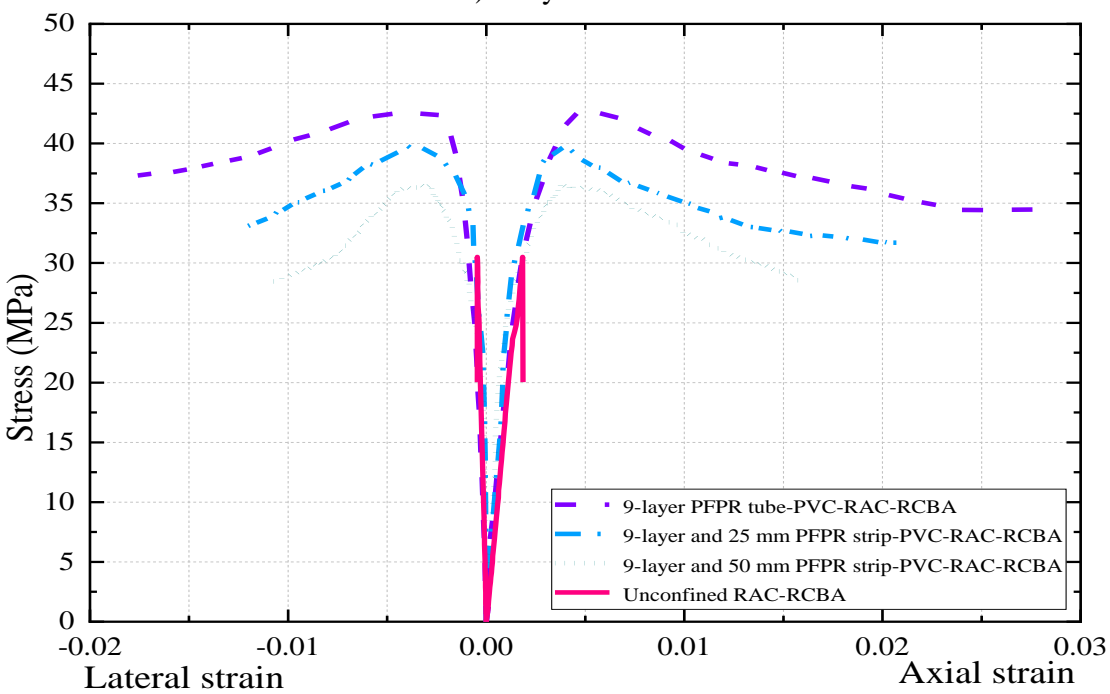

c) 9-layer PFRP

Fig. 17 Compressive stress-strain curves of different spacing distance of PFRP strip-PVC confined RAC-RCBA cylinders

\subsection{Discussion on tested results}

3.3.1 Load carrying capacity and ductility analysis 
All the tested results are listed in Table 6 , where $f_{c o}$ and $\varepsilon_{\text {co }}$ are the peak stress and corresponding axial strain of unconfined RAC-RCBA, respectively, $f_{c t}$ and $\varepsilon_{l}$, $\varepsilon_{\text {ct }}$ are the peak stress, corresponding lateral and axial strain of confined specimens, $f_{c u}$ and $\varepsilon_{\mathrm{cu}}$ are the ultimate stress and corresponding ultimate axial strain of the confined specimens. The lateral confining pressure $f_{l}$ is calculated as Eq. (1) [21], where the $f_{\text {frp }}$ and $t_{\text {frp }}$ are the tensile strength and thickness of the FRP or PVC, respectively, $d$ is the diameter of the concrete cylindrical specimens.

$$
f_{l}=2 f_{\text {frp }} t_{f r p} / d
$$

Table 6 Tested results

\begin{tabular}{ccccccccc}
\hline Specimen & $\begin{array}{c}f_{c o} \\
(\mathrm{MPa})\end{array}$ & $\begin{array}{c}\varepsilon_{\mathrm{co}} \\
\left(10^{-2}\right)\end{array}$ & $\begin{array}{c}f_{c t} \\
(\mathrm{MPa})\end{array}$ & $\begin{array}{c}\varepsilon_{\mathrm{ct}} \\
\left(10^{-2}\right)\end{array}$ & $\begin{array}{c}\varepsilon_{l} \\
\left(10^{-2}\right)\end{array}$ & $\begin{array}{c}f_{l} \\
(\mathrm{MPa})\end{array}$ & $\begin{array}{c}f_{c u} \\
(\mathrm{MPa})\end{array}$ & $\begin{array}{c}\varepsilon_{\mathrm{cu}} \\
\left(10^{-2}\right)\end{array}$ \\
\hline RAC-RCBA & 30.6 & 0.2 & - & - & - & - & - & - \\
PVC-RAC-RCBA & 30.6 & 0.2 & 30.6 & 0.21 & 0.02 & 1.20 & 6.4 & 0.79 \\
PFRP-RAC-RCBA & 30.6 & 0.2 & 38.4 & 0.30 & 0.14 & 2.31 & 28.2 & 2.55 \\
3P-T & 30.6 & 0.2 & 37.1 & 0.36 & 0.18 & 2.32 & 24.5 & 1.64 \\
3P-S25 & 30.6 & 0.2 & 33.1 & 0.26 & 0.16 & 1.64 & 20.8 & 1.25 \\
3P-S50 & 30.6 & 0.2 & 31.9 & 0.21 & 0.12 & 1.44 & 13.3 & 1.00 \\
6P-T & 30.6 & 0.2 & 40.9 & 0.45 & 0.28 & 3.73 & 28.3 & 2.54 \\
6P-S25 & 30.6 & 0.2 & 39.3 & 0.34 & 0.21 & 2.21 & 20.9 & 1.75 \\
6P-S50 & 30.6 & 0.2 & 36.0 & 0.29 & 0.08 & 1.78 & 20.4 & 1.20 \\
9P-T & 30.5 & 0.2 & 42.6 & 0.50 & 0.32 & 5.17 & 34.7 & 2.84 \\
9P-S25 & 30.5 & 0.2 & 39.8 & 0.41 & 0.40 & 2.79 & 31.7 & 2.02 \\
9P-S50 & 30.5 & 0.2 & 36.5 & 0.38 & 0.30 & 2.12 & 28.4 & 1.59 \\
\hline
\end{tabular}

According to the tested results, the increments in the compressive strength enhancement at TP point in Fig. 15 by the different confinements can be calculated. The corresponding increase ratios of different confined RAC-RCBA referring to the unconfined RAC-RCBA can be obtained and are listed in Fig. 18 which shows that the PVC tube confinement did not provide enhancement in the compressive strength of the RAC-RCBA, which may be attributed to the very low confining pressure provided by the PVC tube, as listed in Eq. (1), the lateral confining pressure is high dependent on the tensile strength and the thickness of the PVC, both of which are relatively small. The 6-layer PFRP tube confinement resulted in a $26 \%$ increase in the compressive strength of the RAC-RCBA. Overall, both PFRP tube-PVC and PFRP strip-PVC confinement enhanced the compressive strength of RAC-RCBA effectively. Comparison of PFRP tube-PVC-RAC-RCBA with different thickness of PFRP tube (i.e., 3P$\mathrm{T}$, 6P-T and 9P-T) demonstrated that with an increase of number of the PFRP layers, the increment of compressive strength of the RAC-RCBA enhanced. For PFRP strip-PVC-RACRCBA specimens with the same strip thickness but different strip spacing (i.e., 3P-S25 and 3P-S50, 6P-S25 and 6P-S50, 9P-S25 and 9P-S50), increasing the spacing distance of the PFRP strip reduced the increments to some extent. Besides, the PFRP tube-PVC-RAC-RCBA had larger compressive strength than the corresponding PFRP strip-PVC-RAC-RCBA with the same PFRP and PVC thickness.

The ductility indices $\mu$ of all the confined specimens in Fig. 19 were calculated as the ratio of the $\varepsilon_{\mathrm{cu}}$ to the $\varepsilon_{\mathrm{co}}$. The PVC-RAC-RCBA showed an obvious improvement in the ductility, which was 4.2. The 6-layer PFRP-RAC-RCBA also had a significantly enhanced ductility index, which was 13.4. Comparison of PFRP tube-PVC-RAC-RCBA (i.e., 3P-T, 6P-T and 9P-T) with different PFRP tube thicknesses demonstrated that with an increase of number of the PFRP layers, the ductility index also increased remarkably. In general, the ductility index of the PFRP tube-PVC-RAC-RCBA specimen was larger than that of the corresponding 
PFRP strip-PVC-RAC-RCBA with the same thickness of PFRP. For the PFRP strip-PVCRAC-RCBA specimens, an increase in the PFRP strip thickness also increased the ductility index remarkably and an increase in the strip spacing reduced the inductility index of the specimen. It should be pointed out here that the comparison in strength and ductility index is based on the limited number of replications and the percentage increments are based on the comparison on average values of tested group.

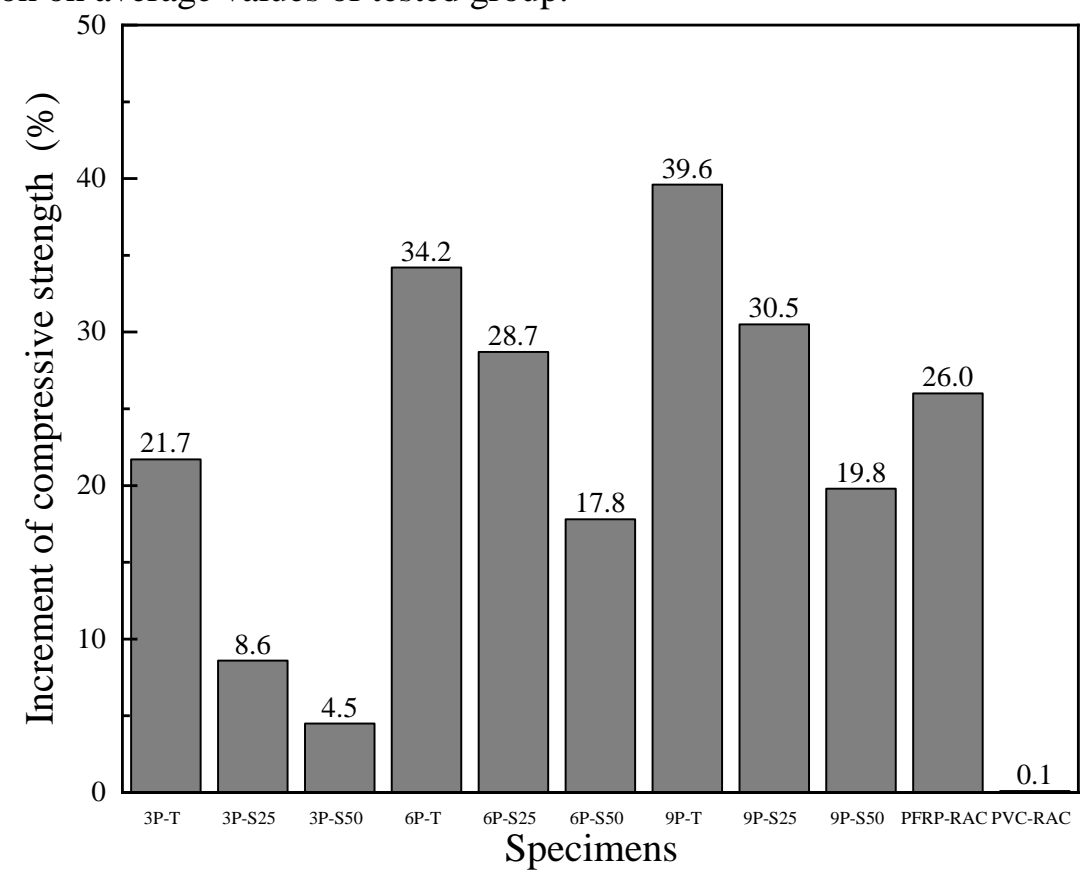

Figure 18: Increment ratios of compressive strength of different confined

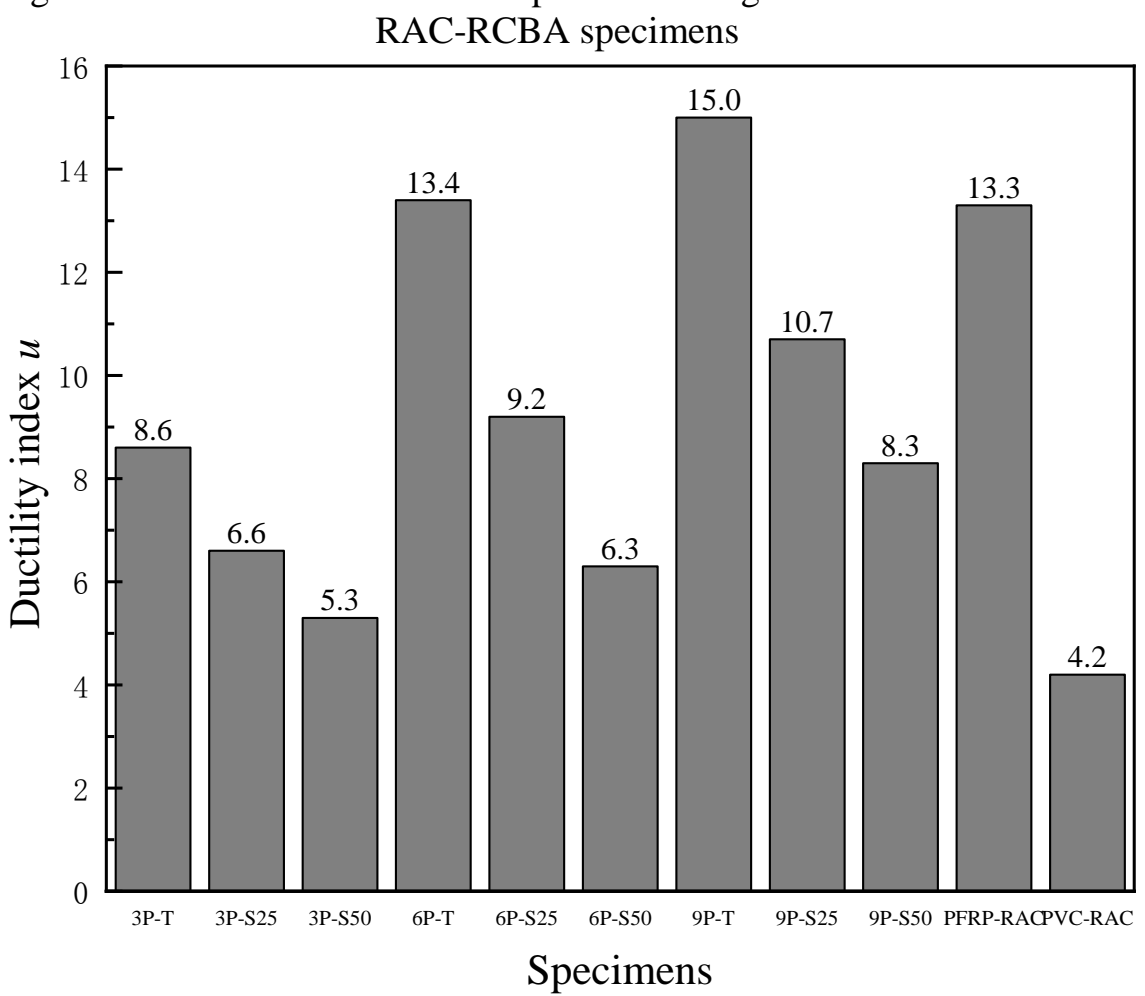

Figure 19. Ductility indexes of the confined specimens 3.3.2 Comparison with GFRP-RAC-RCBA and CFRP-RAC-RCBA

501 In this section, the results of current study were compared with those of GFRP tube encased 
unconfined RAC-RCBA, the replacement ratio of RAs for the RAC-RCBA, the constitutive of the RAs, and the size of the RAC-RCBA used in Ref. [21] were similar as those used in current study. The comparison in results of 6-layer CFRP-RAC-RCBA, 6-layer GFRP-RACRCBA, 6-layer PFRP-RAC-RCBA and 6-layer PFRP tube-PVC-RAC-RCBA is listed in Table 7. The comparison in the tensile properties of PFRP, PVC, GFRP and CFRP can be found in Table 5 .

The comparison indicated that the 6-layer CFRP or 6-layer GFRP tube encased RAC-RCBA had much higher compressive strength than that of 6-layer PFRP-RAC-RCBA or 6-layer PFRP tube-PVC-RAC-RCBA, while the ductility indices of 6-layer CFRP-RAC-RCBA and 6-layer GFRP-RAC-RCBA were much lower than that of the 6-layer PFRP-RAC-RCBA or 6-layer PFRP-PVC-RAC-RCBA. The confinement ratio is defined as $f_{c u} / f_{c o}$ to evaluate the effectiveness of FRP confinement on concrete, and the ratios of confinement ratio and cost were calculated to compare the cost performance as Table 7. Although the confinement ratios of PFRP-RAC-RCBA and PFRP tube-RAC-RCBA are lower than those of CFRP-RACRCBA and GFRP-RAC-RCBA, the ratios of confinement ratio and cost of PFRP-RACRCBA and PFRP tube-PVC-RAC-RCBA are much higher than those of CFRP-RAC-RCBA and GFRP-RAC-RCBA.

Table 7 Comparison of CFRP, GFRP and PFRP tube confined RAC-RCBA

\begin{tabular}{ccccccccccc}
\hline Specimens & $\begin{array}{c}f_{c o} \\
(\mathrm{MPa})\end{array}$ & $\begin{array}{c}\varepsilon_{c o} \\
(\%)\end{array}$ & $\begin{array}{c}f_{c u} \\
(\mathrm{MPa})\end{array}$ & $\begin{array}{c}\varepsilon_{c u} \\
(\%)\end{array}$ & $\mu$ & $\begin{array}{c}f_{l} \\
(\mathrm{MPa})\end{array}$ & $f_{l} / f_{c o}$ & $f_{c u} / f_{c o}$ & $\begin{array}{c}\text { Price of } \\
\text { fibers } \\
\left(\mathrm{RMB} / \mathrm{m}^{2}\right)\end{array}$ & $\begin{array}{c}\text { Confinement } \\
\text { ratio/Cost }\end{array}$ \\
\hline $\begin{array}{c}\text { 6L-CFRP- } \\
\text { RAC-RCBA } \\
\begin{array}{c}\text { 6L GFRP- } \\
\text { RAC-RCBA } \\
\text { 6L PFRP- }\end{array}\end{array}$ & 33.3 & 0.3 & 161.3 & 1.71 & 5.6 & 40.7 & 1.22 & 4.84 & $\begin{array}{c}\text { Glass fibre } \\
80\end{array}$ & 0.61 \\
$\begin{array}{c}\text { PVC-RAC- } \\
\text { RCBA }\end{array}$ & 30.5 & 0.2 & 40.9 & 2.54 & 13.4 & 3.7 & 0.12 & 1.34 & $\begin{array}{c}\text { Polyester } \\
\text { fibre } 1.1\end{array}$ & 1.22 \\
$\begin{array}{c}\text { 6L PFRP- } \\
\text { RAC-RCBA }\end{array}$ & 30.5 & 0.2 & 38.4 & 2.55 & 13.3 & 3.2 & 0.10 & 1.26 & $\begin{array}{c}\text { Polyester } \\
\text { fibre } 1.1\end{array}$ & 1.14 \\
\hline
\end{tabular}

\subsection{Dilation behavior}

In this section, the discussion on the dilation behavior of PFRP-PVC-RAC-RCBA specimens is presented. The dilation effect was caused by the expansion of the core concrete when the applied stress was close to or exceeded the ultimate axial stress of the concrete and then the outer confining tubes were activated to dilate. The dilation rate $\mu_{t}$ is expressed as the slope of the lateral strain increment to axial strain increment and given as Eq. (2) [67]. The corresponding dilation rates of PFRP-PVC-RAC-RCBA are presented in Fig.20.

$$
\mu_{t}=\Delta \varepsilon_{\mathrm{h}} / \Delta \varepsilon_{c}
$$

As illustrated in Fig.20, the peak dilation rate of PVC-RAC-RCBA is considerable indicating the significant improvement in ductility due to the PVC confinement (as illustrated in Fig 19). The peak dilation rate of the 6-layer PFRP-RAC-RCBA is like that of 6-layer PFPR tubeRAC-RCBA. For PFRP tube-PVC-RAC-RCBA with different PFRP thicknesses (i.e., 3P, 6P and 9P), both the ultimate axial strains and the peak dilation rates increase with an increase of the PFRP thickness. For PFPR strip-PVC-RAC-RCBA with different strip spacing (i.e., 3PS25 and 3P-S50, 6P-S25 and 6P-S50, 9P-S25 and 9P-S50), a decrease of spacing distance of the PFRP strip enhances the peak dilation rate with more ductile characteristic of specimens. In addition, the PFRP tube-PVC-RAC-RCBA specimens always present larger dilation rate than the corresponding PFRP strip-PVC-RAC-RCBA specimens with the same PFRP thickness. 


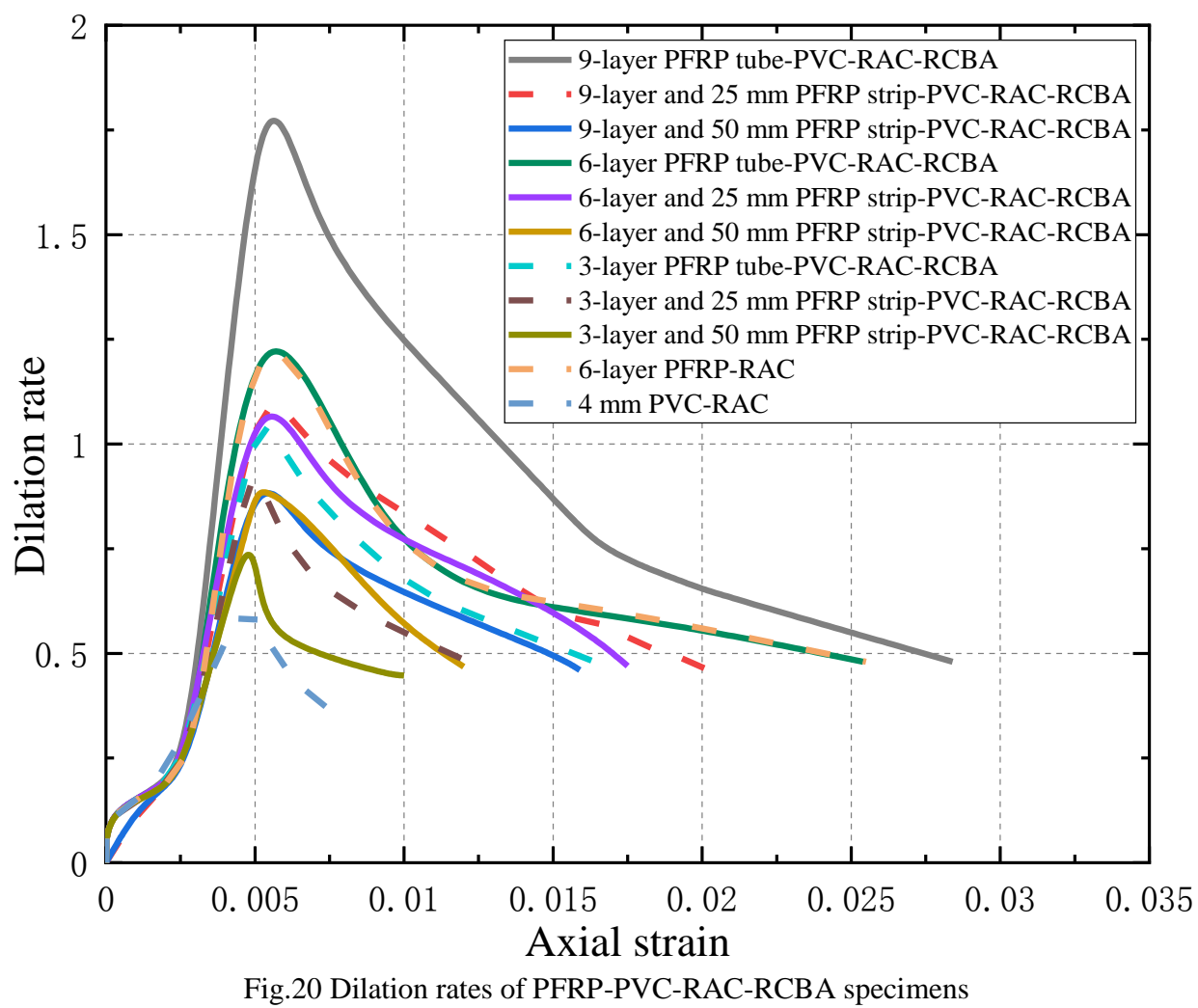

\subsection{Axial strain at mid height and ends of the tubes}

544 The average axial strains at the mid height and ends of the PFRP tube-PVC-RAC-RCBA specimens (i.e., 3P-T 6P-T and 9P-T specimens) were obtained from the four strain gauges at the mid height on the surface of the PFRP tube (i.e., SG5, SG6, SG7 and SG8, see Fig 12) and four axial strain gauges at both the ends at the surface of the PFRP tube (i.e., SG9, SG10, SG11 and SG12, see Fig 12). The comparisons of the stress and axial strain at the mid height and both ends of specimens (i.e., 3P-T, 6P-T and 9P-T) are shown in Fig. 21. Generally, the overall tendency of the stress-strain behavior at the middle region of specimens is similar to that at the ends of specimens. Apparently, the axial deformation at the middle region of specimens is larger than that at the ends of specimens under the same stress. The possible reasons include: (1) the larger expansion of core concrete at the middle region under the compression, and (2) the existing of two extra PFRP strip strengthening at both the ends of specimens in order to avoid premature rupture of ends of specimens. The difference in the axial strain between the mid-height and ends of specimens was more pronouncedly for specimens with less thick of the PFRP tube. 


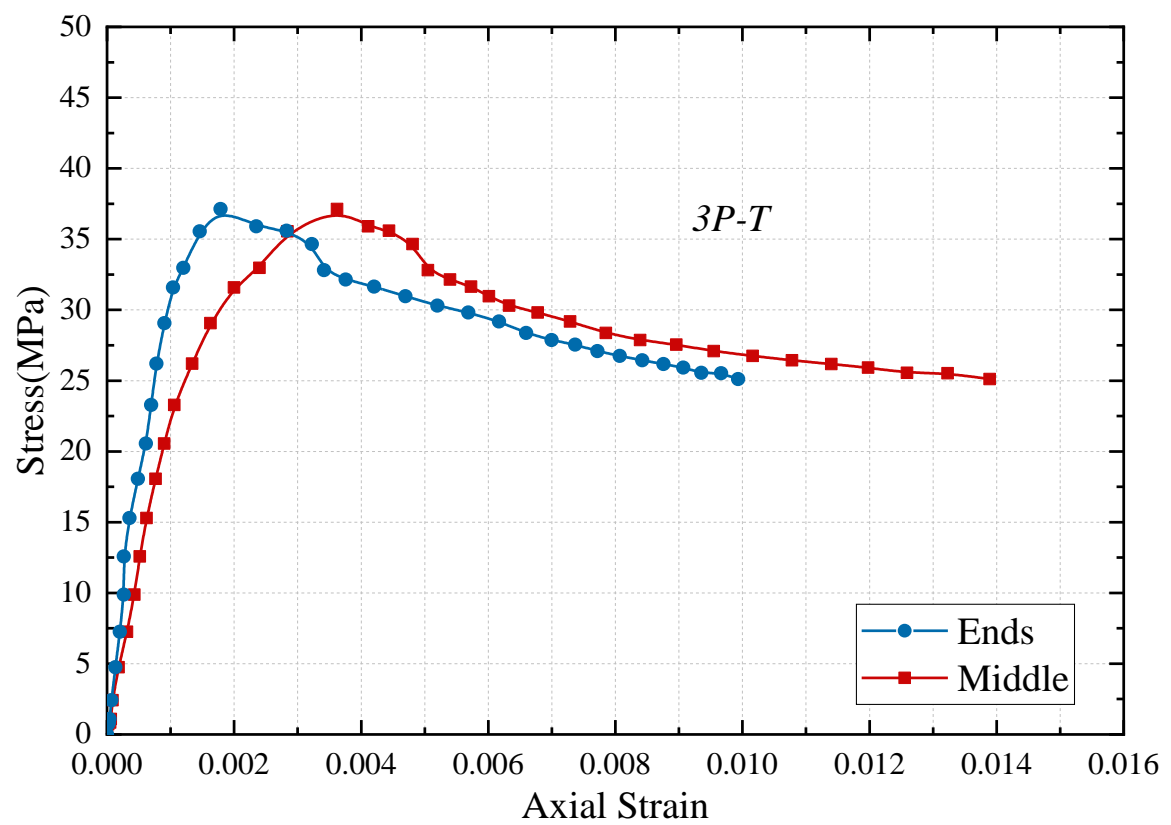

a) 3-layer PFRP

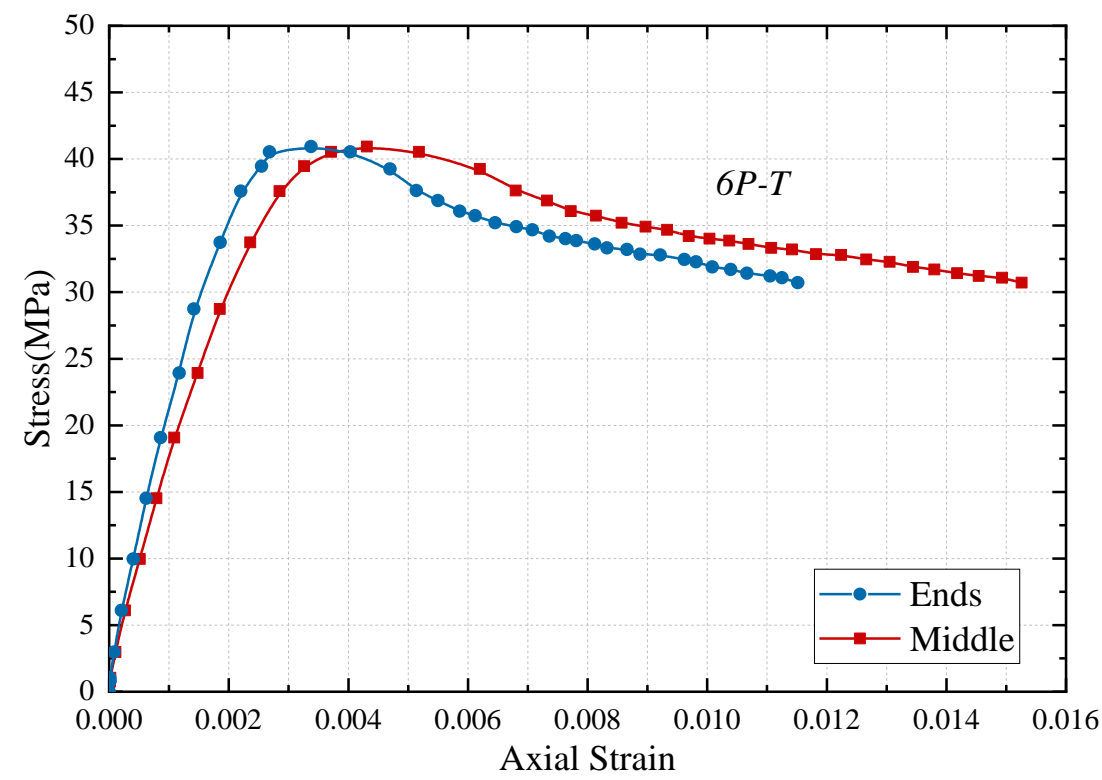

b) 6-layer PFRP 


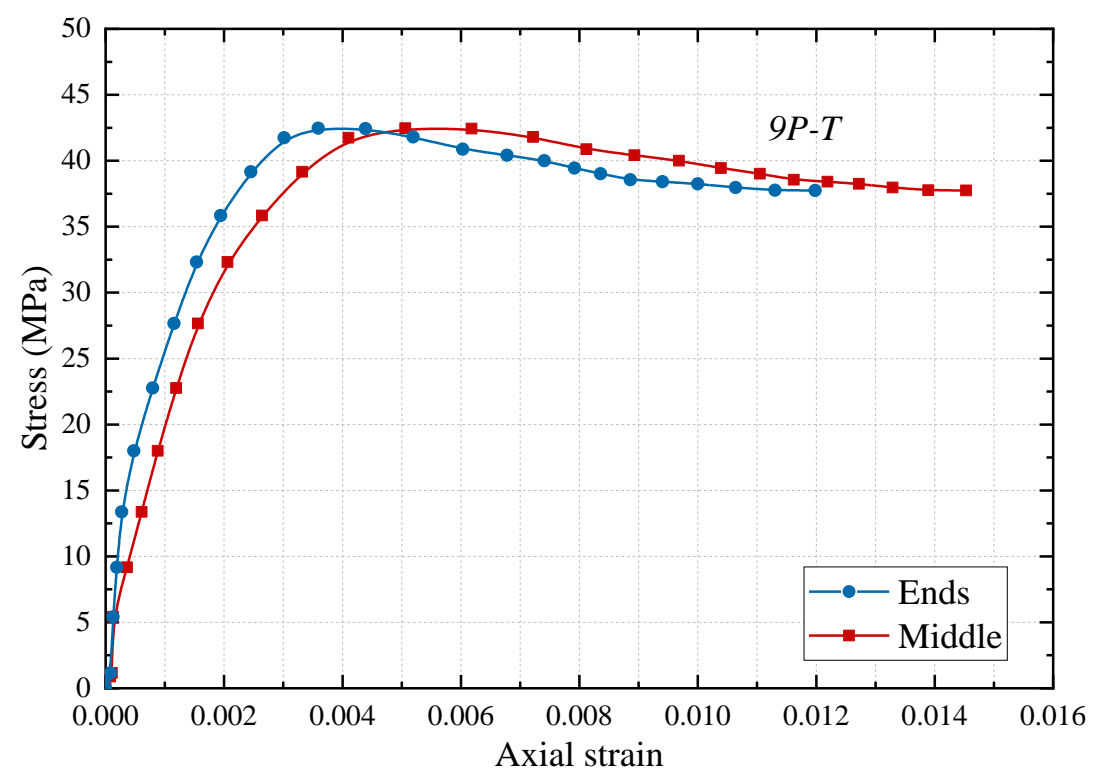

c) 9-layer PFRP

Fig.21 End and middle stress-strain curves of PFRP tube-PVC- RAC-RCBA cylinders

\section{Analytical modeling of PFRP-PVC-RAC-RCBA}

4.1 Mechanical characteristics analysis of PFRP-PVC-RAC-RCBA in compression

For the purpose of designing PFRP-PVC-RCBA-RCBA structures for practical application, accurate stress-strain models should be developed. To develop stress-strain models, it is important for us to understand the mechanical characteristics of PFRP-PVC-RAC-RCBA in axial compression. In this study, the mechanical characteristics analysis of PFRP-PVC-RACRCBA in axial compression followed the mechanical analysis of FRP-steel tube confined concrete introduced by Teng et al. [60]. With the similar analysis, the mechanical characteristics of PFRP-PVC-RAC-RCBA in axial compression can be obtained and is illustrated in Fig.22. The core concrete is under a tri-axial compression state, therefore the load carrying capacity and deformation capacity of the concrete are enhanced. From Fig. 22, it is clear that both PFRP and the PVC provided the lateral confining pressure to the concrete core, as expressed by Eq. (3):

$$
f_{l}^{\prime}=f_{l f}+f_{l p}
$$

As shown in Fig 22(b), the force equilibrium in the PVC tube can be expressed by Eq. (4):

$$
f_{l p}=\frac{2 E_{P V C} \varepsilon_{P V C} t_{P V C}}{d}
$$

As shown in Fig 22(a), the force equilibrium in the PFRP section can be expressed by Eq. (5):

$$
f_{l f}=\frac{2 E_{f r p} \varepsilon_{f r p} t_{f r p}}{d+2 t_{P V C}}
$$

Where $f_{l}^{\prime}$ is the lateral confining pressure of the composite confinement on concrete core, $f_{l f}$ is the effective lateral confining pressure provided by PFRP, $f_{l p}$ is lateral confining pressure provided by PVC, $E_{p v c}, \varepsilon_{p v c}$, and $t_{p v c}$ are the elastic modulus, tensile strain in the hoop direction and thickness of the PVC tube, $E_{f p p}, \varepsilon_{f i p}$, and $t_{f r p}$ are the elastic modulus, tensile strain in the hoop direction and thickness of PFRP tube, $d$ is the diameter of the core concrete.

For PFRP strip-PVC-RAC-RCBA cylinders, the equivalent PFRP thickness $t_{f i p}$ ' can be written by Eq.(6):

$$
t_{f r p}^{\prime}=\frac{n b_{f r p}}{H} t_{f r p}
$$

Then, the force equilibrium of the PFRP strip confinement can be written as following Eq.(7)::

$$
f_{l f}=\frac{2 n E_{f r p} \varepsilon_{f r p} b_{f r p} t_{f r p}}{H\left(d+2 t_{P V C}\right)}
$$

Where $n$ is the number of PFRP strips, $b_{f p p}$ is the width of PFRP strip, $H$ is the height of concrete cylinders. The lateral confining pressure provided by the PFRP strips was imposed onto the concrete core through the PVC to, the dispersion angle was $45^{\circ}$ and the dispersion 


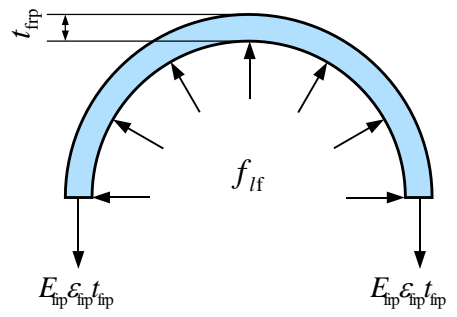

a) Force equilibrium of PFRP

width was the thickness of the PVC tube (Fig 23), as explained by Teng et al. [65]. Thus, the effective lateral confining pressure onto the concrete core can be expressed by

$$
\begin{gathered}
f_{l f}^{\prime}=k_{e} f_{l f} \\
k_{e}=\frac{A_{e}}{A} \\
\mathrm{~A}_{\mathrm{e}}=\mathrm{A}-\mathrm{m} \frac{\left(\mathrm{s}-2 \mathrm{t}_{\mathrm{pvc}}\right)^{2}}{2} \\
A=d H
\end{gathered}
$$

Where $k_{e}$ is the effective confining coefficient of the PFRP strip, and $k_{e}=1$ is for PFRP tube confinement, $A e$ is the effective confining area of the core concrete, $A$ is the gross area of specimens including the core concrete and external hybrid tube, $m$ is the number of zone without confinement among PFRP strip, $s$ is the spacing distance of the PFRP strip. Overall, the Eq.(3) can be expressed as Eq.(12):

$$
f_{l}^{\prime}=f_{l f}^{\prime}+f_{l p}=k_{e} f_{l f}+f_{l p}
$$

Specifically, for PFRP tube-PVC-RAC-RCBA cylinders:

$$
f_{l}^{\prime}=\frac{2 E_{f r p} \varepsilon_{f r p} t_{f r p}}{d+2 t_{P V C}}+\frac{2 E_{P V C} \varepsilon_{P V C} t_{P V C}}{d}
$$

For PFRP strip-PVC-RAC-RCBA cylinders:

$$
f_{l}^{\prime}=k_{e} \frac{2 n E_{f r p} \varepsilon_{f r p} t_{f r p}}{H\left(d+2 t_{P V C}\right)}+\frac{2 E_{P V C} \varepsilon_{P V C} t_{P V C}}{d}
$$

$\begin{array}{lll}m \text { of PFRP } & \text { b) Force equilibrium of PVC } & \text { c) Force equilibrium } \\ \text { Fig.22 Mechanical characteristics of PFRP tube-PVC-RAC-RCBA cylinder }\end{array}$

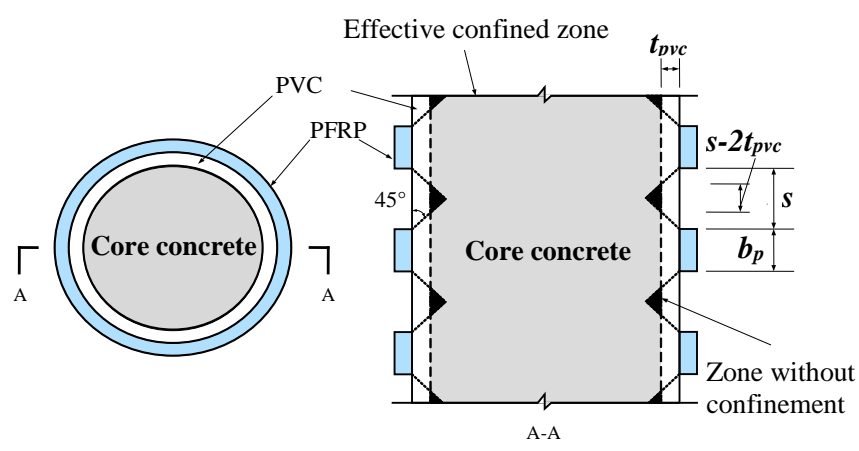

Fig.23 Mechanical characteristics of PFRP strip-PVC- RAC-RCBA cylinder
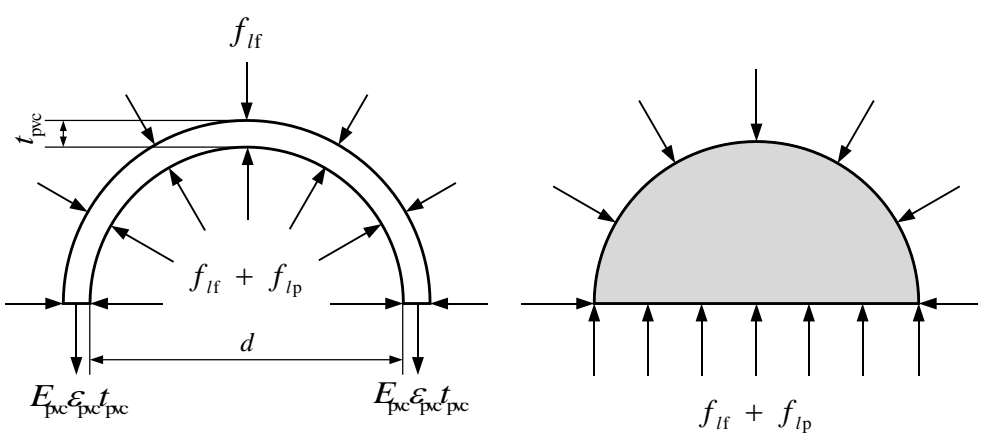

c) Force equilibrium of RAC-RCBA 
was cited as Eq.(15) [62] for better expressing the relationship of ultimate stress and the elastic modulus of confined materials and core concrete:

$$
\lambda=\frac{E_{l}}{E_{c}}
$$

618 Where $E_{c}$ is the elastic modulus of the RAC-RCBA which is related to the square root of compressive strength $\sqrt{f_{c o}}[61,62]$ as Eq.(16), $E_{l}$ is the effective lateral confining stiffness of the hybrid PFRP-PVC tube which is expressed as Eq.(17) and Eq.(18):

$$
\lambda=\frac{E_{l}}{\sqrt{f_{c o}}}
$$

The strength $f_{\mathrm{cc}}$ ' and corresponding strain $\varepsilon_{\mathrm{cc}}{ }^{\prime}$ could be calculated as:

$$
E_{l}=k_{e} \frac{2 n E_{f r p} t_{f r}}{H\left(d+2 t_{P V C}\right)}+\frac{2 E_{P V C} t_{P V C}}{d} \text { (For PFRP strip-PVC-RAC-RCBA) }
$$

$$
\begin{aligned}
& \frac{f_{c c}^{\prime}}{f_{c o}}=1+k_{1}\left(\frac{\lambda}{f_{c o}}\right)^{\alpha} \\
& \frac{\varepsilon_{c c}^{\prime}}{\varepsilon_{c o}}=1+k_{2}\left(\frac{\lambda}{\varepsilon_{c o}}\right)^{\beta}
\end{aligned}
$$

Based on the regression analysis and iterative computations of the tested results, the fitting coefficients $\alpha=0.622$ and $k_{l}=0.405, \beta=0.684$ and $k_{2}=1.647$ can be determined to create the strength and strain equations for PFRP-PVC-RAC-RCBA, as illustrated in Fig 24. The strength and peak strain models for PFRP-PVC-RAC-RCBA can be expressed by Eq.(21) and (22):

633

$$
\begin{aligned}
& \frac{f_{c c}^{\prime}}{f_{c o}}=1+0.405\left(\frac{\lambda}{f_{c o}}\right)^{0.622} \\
& \frac{\varepsilon_{c c}^{\prime}}{\varepsilon_{c o}}=1+1.647\left(\frac{\lambda}{\varepsilon_{c o}}\right)^{0.684}
\end{aligned}
$$

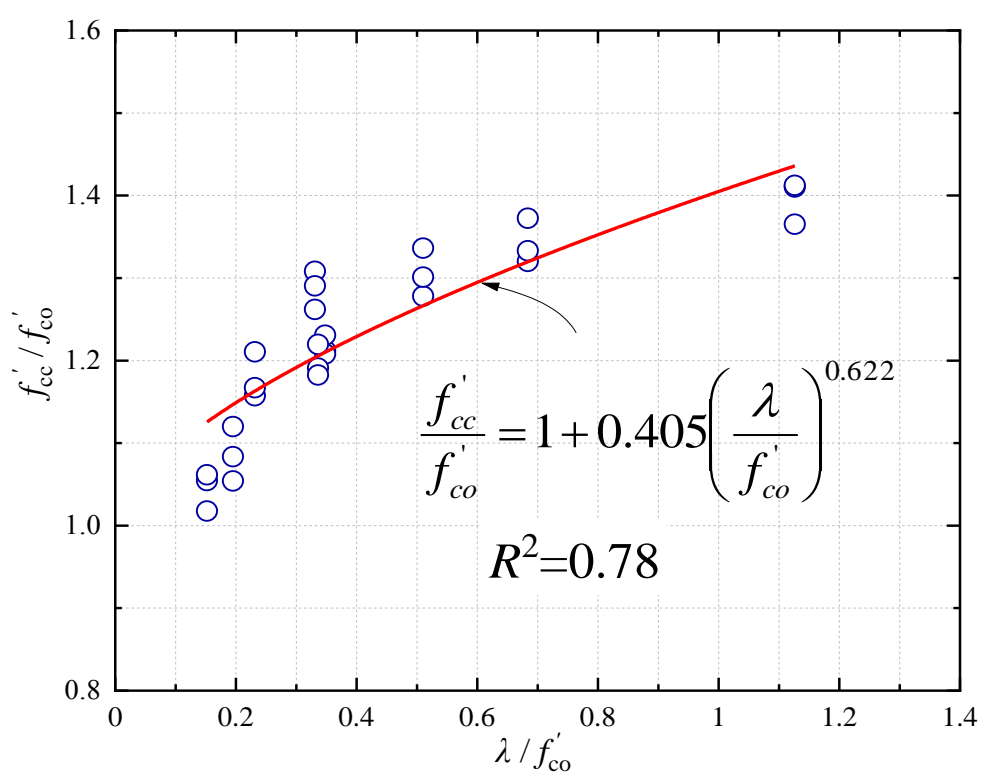

a) Fitting curves of strength model 


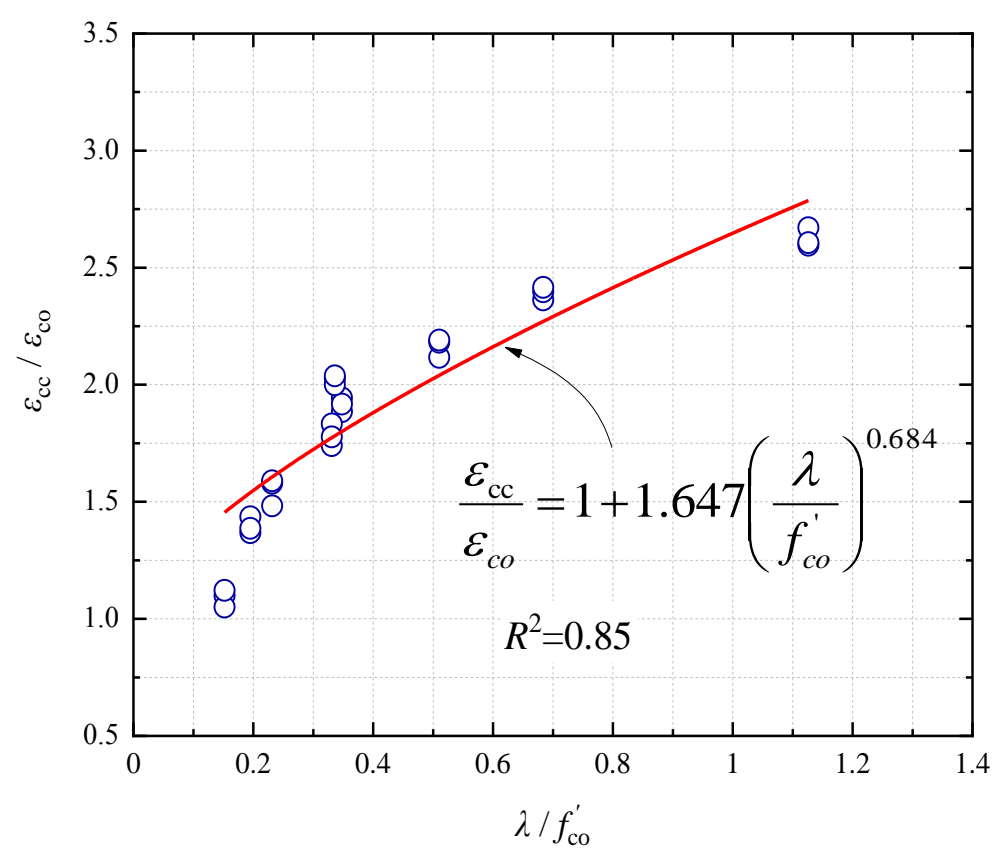

b) Fitting curves of peak strain model

Fig. 24 Fitting curves of peak strength models

Based on the stress and strain equations above, the comparison in the peak strength and the peak axial strain between the experimental and predictions is shown in Fig 25. It can be seen that the predictions based on the developed stress and strain models matched the experimental stress and strain values of the PFRP-PVC-RAC-RCBA well, with relatively small deviations.

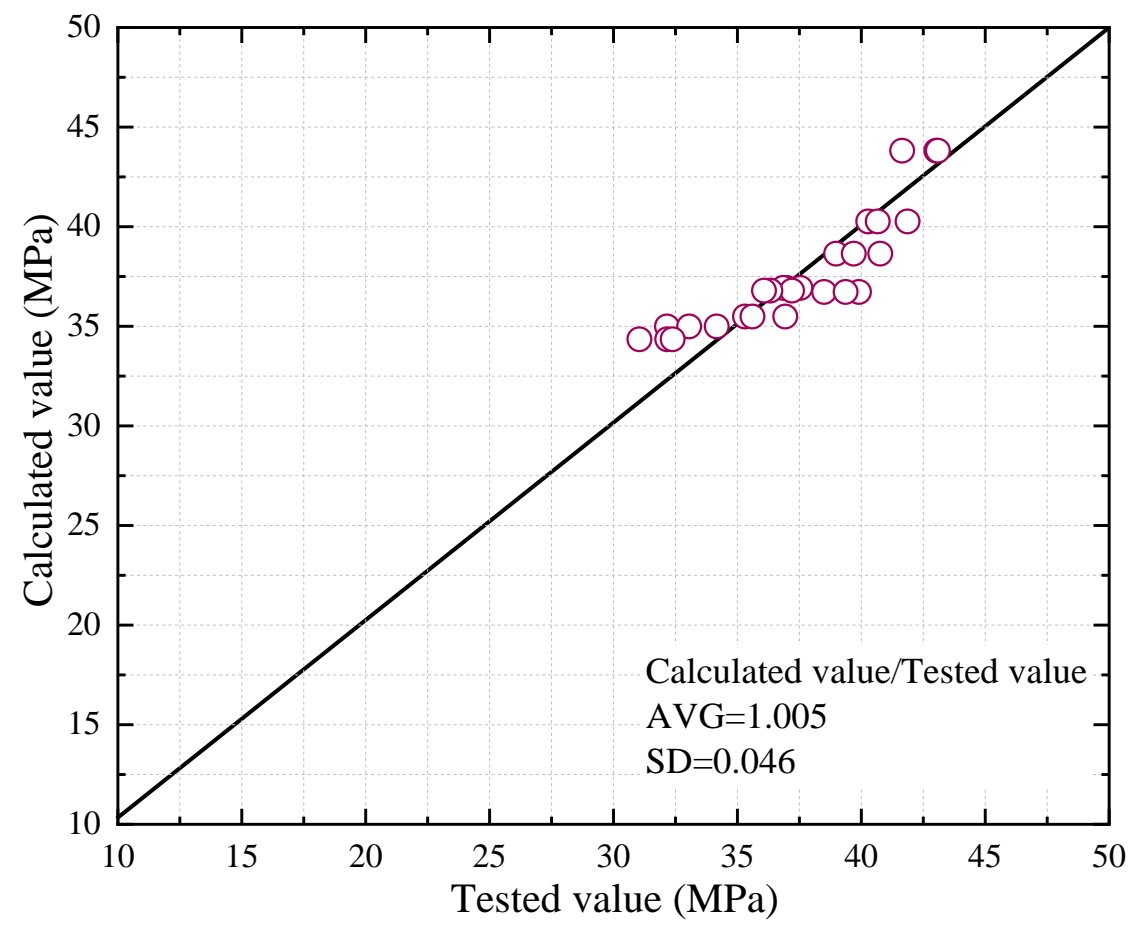

a) Performance of strength model 


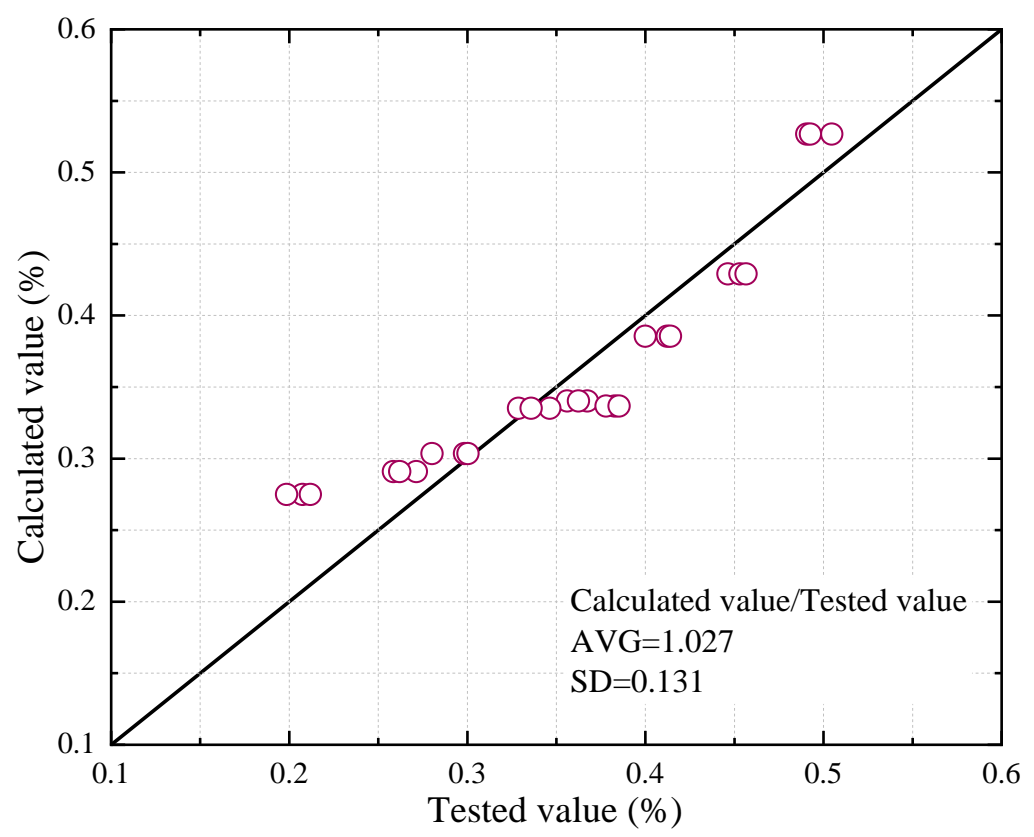

b) Performance of peak strain model

Fig. 25 Performance of peak strength models: strength and peak strain models

\subsection{Ultimate strain and corresponding stress models}

In literature, the ultimate strain and corresponding stress models for FRP confined concrete typically had the following expressions [63, 64]:

$$
\begin{aligned}
& \frac{f_{c u}^{\prime}}{f_{c o}}=c_{1}+k_{3}\left(\frac{f_{l}}{f_{c o}}\right)^{b_{1}} \\
& \frac{\varepsilon_{c u}^{\prime}}{\varepsilon_{c o}}=c_{2}+k_{4}\left(\frac{f_{l}}{f_{c o}}\right)^{b_{2}}
\end{aligned}
$$

640 Where $f_{c u}^{\prime}$ and $\varepsilon_{\mathrm{cu}}^{\prime}$ are the ultimate stress and the corresponding ultimate strain of PFRP-

PVC-RAC-RCBA as UP point in Fig.15. Based on the regression analysis and iterative computations of the partial tested results, the fitting coefficients $c_{1}=1.17, b_{1}=-1.665$ and $k_{3}=-$ $0.0043, c_{2}=1, b_{2}=0.817$ and $k_{4}=63.64$ can be determined to create the strain equations for PFRP-PVC-RAC-RCBA, as illustrated in Fig.26. The strength and peak strain models can be

$$
\begin{gathered}
\frac{f_{c u}^{\prime}}{f_{c o}}=1.17-0.0043\left(\frac{f_{l}}{f_{c o}}\right)^{-1.665} \\
\frac{\varepsilon_{c u}^{\prime}}{\varepsilon_{c o}}=1+63.64\left(\frac{f_{l}}{f_{c o}}\right)^{0.817}
\end{gathered}
$$




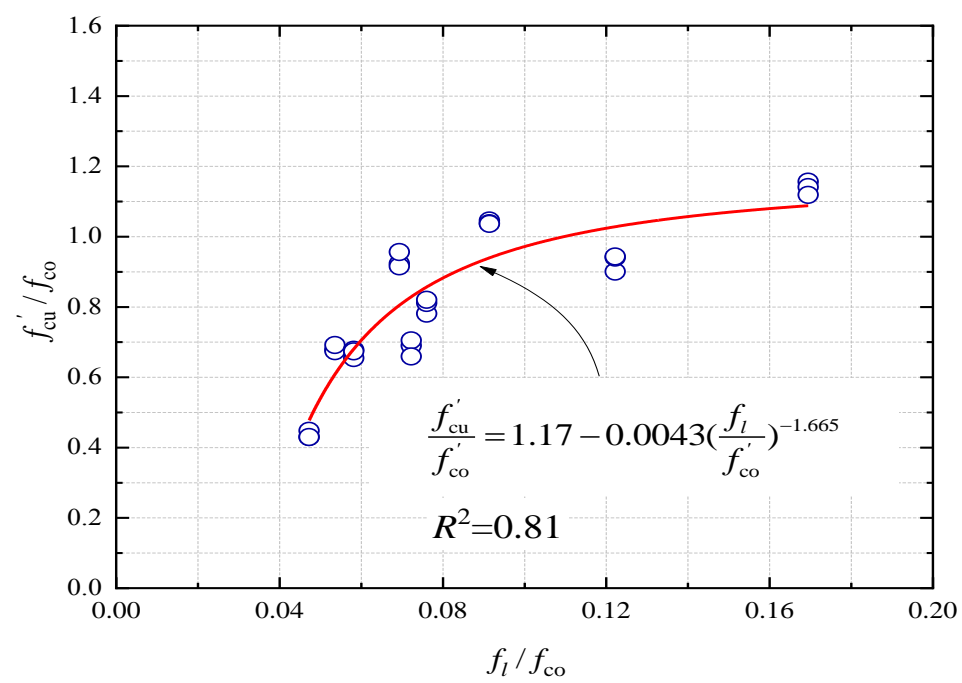

a) Fitting curves of ultimate stress model

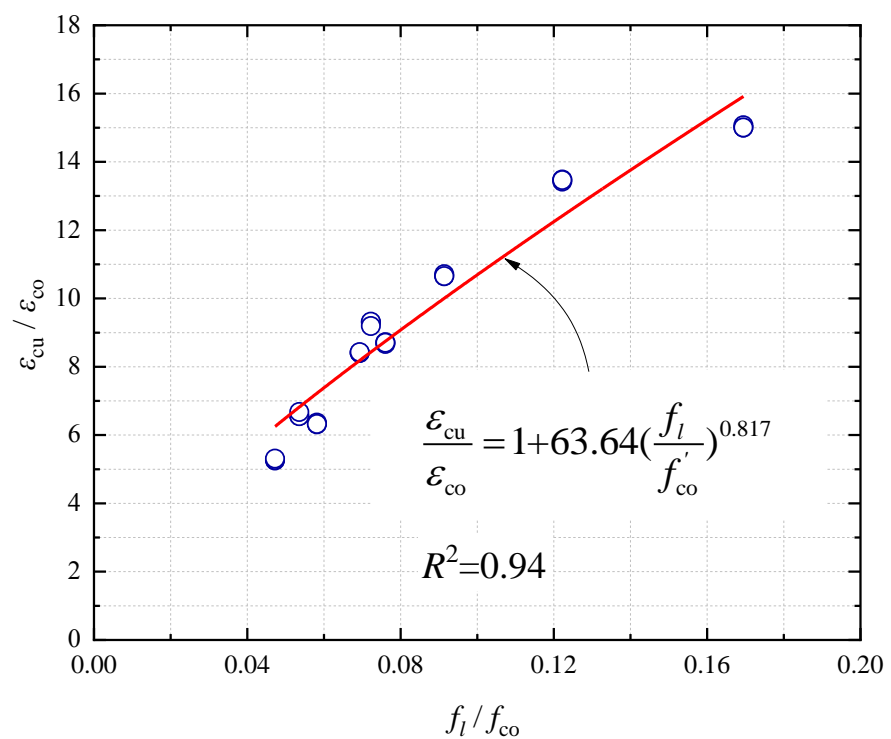

b) Fitting curves of ultimate strain model

Fig.26 Fitting curves of ultimate models

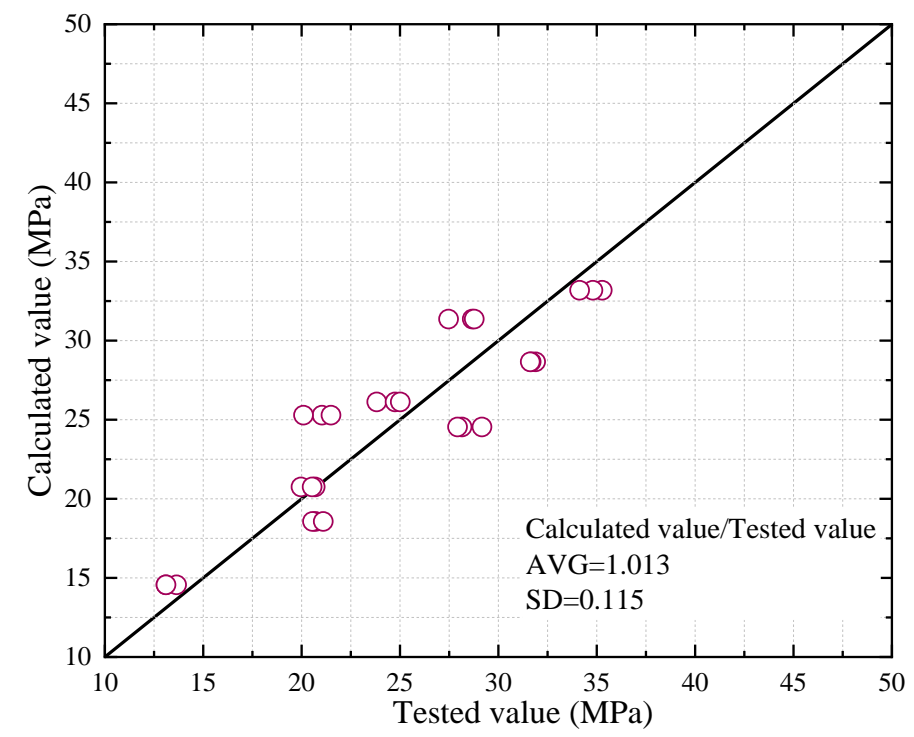

a) Fitting curves of ultimate stress model 


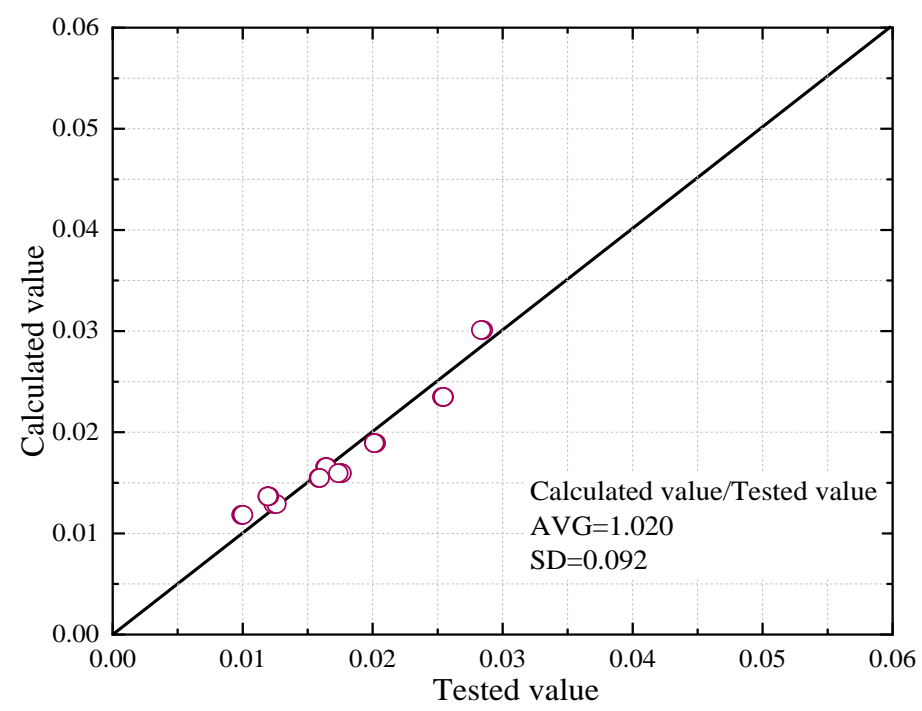

b) Fitting curves of ultimate strain model

Fig.27 Fitting curves of ultimate models

Based on the ultimate stress and strain equations above, the comparison in the ultimate stress and the ultimate axial strain between the experimental and predictions is shown in Fig 27. It can be seen that the predictions based on the developed stress and strain models matched the experimental stress and strain values of the PFRP-PVC-RAC-RCBA well, with relatively small deviations.

\section{Conclusions}

This paper investigated the axial compression behavior of polyester FRP-PVC tube encased recycled aggregate concrete (RAC) with recycled clay brick aggregates (RCBA). Two experimental phases were carried out. In the first stage, different replacement ratios of recycled aggregates and different cement-water ratios for RAC-RCBAs were considered in order to find out the optimized relationship between the strength of RAC and replacement ratios and cement-water ratios. In the second stage, experimental works were carried out to investigate the effects of type of PFRP confinement (i.e. tube and strip), PFRP thickness and spacing of PFRP strips on the axial compressive behavior of PFRP-PVC-RAC-RCBA specimens. The study reveals that:

1. The compressive strength of RAC-RCBA decreased with an increase of the water-cement ratios. The RAC-RCBA with $70 \%$ replacement ratio of RAs obtained the highest compressive strength. In general, the compressive strengths of all the RAC-RCBAs were lower than that of the NAC. The failure mode of RAC-RCBA was similar to that of NAC. However, the close-up showed that most of the RCBA coarse aggregates in the RAC were broken under compression but this was not observed for the natural coarse aggregates in the NAC. This is attributed to the much larger crushing of the RAs with RCBA than that of the NAs for NAC.

2. The PFRP tube, PFRP-strip-PVC tube and PFRP-tube-PVC tube confinement all increased the load carrying capacity and ductility of the RAC-RCBA remarkably. The PVC tube confinement did not show enhancement in the compressive strength but resulted in significant enhancement in the ductility. In general, the enhancement in compressive strength and ductility by PFRP-PVC tube dual confinement was larger than those of the corresponding PFRP or PVC tube single confinement, i.e. the increment in strength of RAC-RCBA by the 6-layer PFRP tube-PVC confinement was $34.2 \%$, while that of RAC-RCBA by 6-layer PFRP or PVC tube alone was $26.0 \%$ and $0.1 \%$, respectively.

3. The improvement on strength and ductility for the RAC-RCBA by the PFRP-PVC confinement was increase with an increasing PFRP tube thickness and a decreasing 
spacing of the PFRP strip. In addition, the PFRP tube-PVC-RAC-RCBA always exhibited higher compressive strength and ultimate strain than those of the corresponding PFRP strip-PVC-RAC-RCBA with the same PFRP thickness. However, the PFRP strip-PVCRAC-RCBA showed the same compressive stress-strain curve pattern with the PFRP tube-PVC-RAC-RCBA.

4. The comparison with the GFRP tube RAC-RCBA and CFRP tube RAC-RCBA showed that GFRP and CFRP confinement resulted in much higher enhancement in the compressive strength compared with PFRP, PVC and PFRP-PVC for RAC-RCBA due to the much larger tensile strength and modulus of the GFRP and CFRP. However, the PFRP and PFRP-PCV confinement resulted in much larger ductility compared with their GFRP and CFRP confinement counterparts.

5. Design-oriented stress-strain models were developed for PFRP-PVC-RAC-RCBA specimens in axial compression. The accuracy of the developed models was verified with the experimental results.

Overall, this study confirmed that the PFRP-PVC-RAC-RCBA hybrid system is quite promising for structural application with desirable carrying capability and ductility characteristic. In the future study, the effects of different experimental parameters such as size effect and slenderness ratio of the specimens on axial compression and even dynamic loading responses need to be evaluated.

\section{Acknowledgement}

This study is supported by National Key Research and Development Program of China (No. 2017YFC0703305) and Federal Ministry of Education and Research of Germany (No. 01DS18023).

\section{References}

[1] Ghisellini P, Ji X, Liu GY, Ulgiati S. Evaluating the transition towards cleaner production in the construction and demolition sector of China: A review. Journal of Cleaner Production 2018;195: 418-434

[2] Nezerka V, Hrbek V, Prosek Z, Somr M. Micromechanical characterization and modelling of cement pastes containing waste marble power. Journal of Cleaner Production 2018;195: 1081-1090.

[3] J.L. Chen. Reconsideration of issues about construction waste recycling. Construction Technology. 2015;58-59.

[4] J.L. Chen, W.J. Zhou, W. Li. Precondition and problems in reutilization of building wastes. Architecture Technology. 2015;46(12):1114-1116.

[5] T.U. Mohammed, A. Hasnat, M.A Awal. Recycling of brick aggregate concrete as coarse aggregate. Journal of Materials in Civil Engineering. 2014;27(7): B4014005.

[6] J. Yang, Q. Du, Y.W. Bao. Concrete with recycled concrete aggregate and crushed clay bricks. Construction and Building Materials. 2011;25:1935-1945.

[7] C.S Poon., Z.H. Shui, L Lam. Effect of microstructure of ITZ on compressive strength of concrete prepared with recycled aggregates. Construction and Building Materials. 2004; 18(6): 461-468.

[8] M. Etxeberria, E. Vázquez, A. Marí. Influence of amount of recycled coarse aggregates and production process on properties of recycled aggregate concrete. Cement and concrete research. 2007;37(5):735-742.

[9] Akhtat A, Sarmah A. Strength improvement of recycled aggregate concrete through silicon rich char derived from organic waste. Journal of Cleaner Production 2018;196: 411-423.

[10] X. Sun, L. Yan, Kasal B. Impact behavior of concrete columns confined by both GFRP tube and steel spiral reinforcement. Construction and Building Materials. 2017;131:438448. 
[11] L. Yan, N. Chouw, K. Jayaraman. Effect of column parameters on flax FRP confined coir fibre reinforced concrete. Construction and Building Materials. 2014;55:299-312.

[12] L. Yan, N, Chouw. Natural FRP tube confined fibre reinforced concrete under pure axial compression: A comparison with glass/carbon FRP. Thin-Walled Structures. 2014;82:159-169.

[13] G. Ma, H. Li. Testing and analysis of basalt FRP-confined damaged concrete cylinders under axial compression loading. Construction and Building Materials. 2018;169:762774.

[14] L. Yan, N. Chouw. Experimental study of flax FRP tube encased coir fibre reinforced composite column. Construction and Building Materials. 2013;40:1118-1127.

[15] A. Duchez. Effect of bond on compressive behavior of flax fibre reinforced polymer tube-confined coir fibre reinforced concrete. Journal of Reinforced Plastics and Composites. 2013;32:273-285.

[16] L. Huang, P. Yin, L. Yan, B. Kasal. Behavior of hybrid GFRP-perforated-steel tube encased concrete under uniaxial compression. Composite Structures. 2016;142:313-324.

[17] C. Gao, L. Huang, L. Yan, G. Ma, L. Xu, Compressive behavior of CFFT with inner steel wire mesh, Composite Structures. 2015;133:322-330.

[18] L. Huang, X. Xun, D. Zhu. Compressive behavior of concrete confined with GFRP tubes and steel spirals. Polymers. 2015;7 (5):851-875.

[19] L. Huang, D. Zhu. Compressive behavior of concrete confined by CFRP and transverse spiral reinforcement. Part A: experimental study. Material Structures. 2016;49(3):10011011.

[20] J. Xiao, Y. Huang, J. Yang. Mechanical properties of confined recycled aggregate concrete under axial compression. Construction and Building Materials. 2012;26(1): 591603.

[21] C. Gao, L. Huang, L. Yan, B. Kasal, W. Li. Behavior of glass and carbon FRP tube encased recycled aggregate concrete with recycled clay brick aggregate. Composite Structures. 2016;155:245-254.

[22] T. Xie, T. Ozbakkaloglu. Behavior of recycled aggregate concrete-filled basalt and carbon FRP tubes. Construction and Building Materials. 2016;105:132-143.

[23] G.M. Chen, Y.H. He, T. Jiang. Behavior of CFRP-confined recycled aggregate concrete under axial compression. Construction and Building Materials. 2016;111:85-97.

[24] M.S.I. Choudhury, A.F.M.S. Amin, M.M. Islam, A. Hasnat. Effect of confining pressure distribution on the dilation behavior in FRP-confined plain concrete columns using stone, brick and recycled aggregates. Construction and Building Materials. 2016:102(1):541551.

[25] Ardavan Yazdanbakhsh, Lawrence C.B. The effect of shear strength on load capacity of FRP strengthened beams with recycled concrete aggregate. Construction and Building Materials. 2016:102(1):133-140.

[26] R.D. Freeman, J.L. Burati, S.N. Amirkhanian. Polyester fibers in asphalt paving mixtures. Association of Asphalt Paving Technologists Proc. 1989;58.

[27] Z. Jing, Z. Bayasi. Properties of polyester fiber reinforced concrete. Journal of Dalian University of Technology. 1993;S2.

[28] T. Ochi, S. Okubo, K. Fukui. Development of recycled PET fiber and its application as concrete-reinforcing fiber. Cement and Concrete Composites. 2007;29(6):448-455.

[29] J.H.J. Kim, C.G. Park, S.W. Lee. Effects of the geometry of recycled PET fiber reinforcement on shrinkage cracking of cement-based composites. Composites Part B: Engineering. 2008;39(3): 442-450.

[30] De Oliveira L.A.P, Castro-Gomes J.P. Physical and mechanical behavior of recycled PET fibre reinforced mortar. Construction and Building Materials. 2011;25(4):1712-1717.

[31] R.P. Borg, O. Baldacchino, L. Ferrara. Early age performance and mechanical characteristics of recycled PET fibre reinforced concrete. Construction and Building Materials. 2016;108:29-47.

[32] J.G. Dai, Y.L. Bai, J.G. Teng. Behavior and Modeling of Concrete Confined with FRP 
Composites of Large Deformability. Journal of Composites for Construction. 2011; 15(6):963-973.

[33] Ispir M. Monotonic and cyclic compression tests on concrete confined with PET-FRP. Journal of Composites for Construction. 2014;19(1): 04014034.

[34] S. Saleem, Q. Hussain, A. Pimanmas. Compressive behavior of PET FRP-confined circular, square, and rectangular concrete columns. Journal of Composites for Construction. 2016;21(3): 04016097.

[35] S. Saleem, A. Pimanmas, W. Rattanapitikon. Lateral response of PET FRP-confined concrete. Construction and Building Materials. 2018;159: 390-407.

[36] A. Pimanmas, S. Saleem. Dilation Characteristics of PET FRP-Confined Concrete. Journal of Composites for Construction. 2018;22(3): 04018006.

[37] L. Huang, X. Yang, L. Yan, K. He, H. Li, Y. Du. Experimental study of polyester fiberreinforced polymer confined concrete cylinders. Textile Research Journal. 2016; 86(15):1606-1615.

[38] L. Huang, L. Chen, L. Yan. Behavior of polyester FRP tube encased recycled aggregate concrete with recycled clay brick aggregate: Size and slenderness ratio effects. Construction and Building Materials. 2017;154:123-136.

[39] T.A. Ranney, L.V. Parker. Susceptibility of ABS, FEP, FRE, FRP, PTFE, and PVC well casings to degradation by chemicals. Cold Regions Research and Engineering Lab Hanover NH. 1995.

[40] Al Malaika S., Golovoy A., Wilkie C.A. Chemistry and technology of polymer additives. Blackwell Science. 1999.

[41] Awham M.H., Salih Z.G.M. A study of some mechanical behavior on a thermoplastic material. Journal of Al-Nahrain University. 2011;14(3):58-65.

[42] Rohe F.P.S. Strength testing of thermal welded PVC geomembrane field seams using non-destructive air channel methods. Environmental Protection, Inc.

[43] Nowack R., Otto O.I., Braun E.W. 60 jahre erfahrungen mit rohrleitungen aus weichmacherfreiem polyvinylchlorid (PVC-U). KRV Nachrichten. 1995;1-95.

[44] Ranne T.A., Parker L.V. Susceptibility of ABS, FEP, FRE, FRP, PTFE, and PVC Well Casing to Degradation by Chemical. Special Report 95-1, US Army Corps of Engineerings, January 1995.

[45] Kurt C. E. Concrete filled structural plastic columns. Journal of the Structural Division, 1978, 104 (ASCE 13478 Proceeding).

[46] H. Toutanji. Behavior of concrete columns encased in PVC-FRP composite tubes. Advanced Materials in Bridges and Structures (ACMBS-III). 2000;809-817.

[47] H. Toutanji, M. Saafi. Durability studies on concrete columns encased in PVC-FRP composite tubes. Composite Structures. 2001;54(1): 27-35.

[48] Toutanji H., Saafi M. Stress-strain behavior of concrete columns confined with hybrid composite materials. Materials \& Structures, 2002, 35(6):338-347.

[49] Wang J., Yang Q. Experimental study on mechanical properties of concrete confined with plastic pipe. ACI Mater J. 2010;107(2).

[50] Gupta P.K., Verma V.K. Study of concrete-filled unplasticized poly-vinyl chloride tubes in marine environment. Proc Inst Mech Eng Part M J Eng Marit Environ. 2014; 1475090214560448 .

[51] Gathimba Naftary K., Oyawa Walter O., Mang'uriu Geoffrey N. Compressive strength characteristics of concrete-filled plastic tubes short columns. Int J Sci Res (IJSR). 2014;3(9):2168-2174.

[52] Jiang S.F., Ma S.L., Wu Z.Q. Experimental study and theoretical analysis on slender concrete-filled CFRP-PVC tubular columns. Construction and Building Materials. 2014;53:475-487.

[53] GB/T 25177-2010. Recycled coarse aggregate for concrete. Standardization Administration of The People's Republic of China. 2011.

[54] D. ASTM. Standard test method for tensile properties of polymer matrix composite materials. 2008. 
[55] GB/T 8804.2-2003. Thermoplastic pipes-Determination of tensile properties-Part 2: Pipes made of unplasticized poly (vinyl chloride) (PVC-U), chloriniated poly (vinyl chloride) (PVC-C) and high-impact poly (vinyl chloride) (PVC-HI). General Administration of Quality Supervision, Inspection and Quarantine of the People's Republic of China. 2003.

[56] Zhao L.J., Weng J.L., Chen W. Test and research on the double horizontal shaft vibrating mixing technology. Construction Machinery Technology and Management. 2013;2:107-110.

[57] Feng X.N., Feng Z.X., Wang W.Z. Review on concrete vibratory mixing techniques. Chinese Journal of Construction Machinery. 2007;5(1):113-116.

[58] T. Ozbakkaloglu. Compressive behavior of concrete-filled FRP tube columns: Assessment of critical column parameters. Engineering Structures. 2013;51:188-199.

[59] M. Fakharifar, G. Chen. Compressive behavior of FRP-confined-filled PVC tubular columns. Composite Structures. 2016;141:91-109.

[60] J.G. Teng, Y. Tao, W.Y. Long, S.L. Dong, Y.F. Yang. Behavior of hybrid FRPconcrete-steel tubular columns: experimental and theoretical studies. Progress in steel building structures. 2006;8(5):1-7.

[61] Pantelides C.P., Yan Z. Confinement model of concrete with externally bonded FRP jackets or post tensioned FRP shells. Journal of Structural Engineering. 2007;133(9):1288-1296.

[62] Xiao Y., Wu H. Compressive behavior of concrete confined by various types of FRP composite jackets. Journal of Reinforced Plastics and Composites. 2003;22(13):11871201.

[63] L. Huang, C. Gao, L.B. Yan, B. Kasal, G. Ma. Reliability assessment of confinement models of carbon fiber reinforced polymer-confined concrete. Journal of Reinforced Plastics and Composites. 2016;0(0):1-31

[64] L. Huang, C. Gao, L.B. Yan, B. Kasal, G. Ma, H.Z. Tan. Confinement models of GFPRconfined concrete: Statistical analysis and unified stress-strain models. Journal of Reinforced Plastics and Composites. 2016;0(0):1-25.

[65] P.P. Li. The research of mechanical behavior of BFRP-PVC tube self-compacting recycled concrete short column under uniaxial compression. Liaoning University of Technology. 2015.

[66] Spoelstra M.R., Monti G. FRP-confined concrete model. Journal of Structural Engineering. 1999;9(4):143-150.

[67] Jian C. Lim, T. Ozbakkaloglu. Lateral strain to axial strain relationship of confined concrete. Engineering Structures. 2015;141(5):04014141.

[68] Riccio A., Di Costanzo C., Di Gennaro P., Sellitto A., Raimondo A. Intra-laminar progressive failure analysis of composite laminates with a large notch damage. Engineering Failure Analysis. 2017;73:97-112.

[69] Riccio A., Sellitto A., Saputo S., Russo A., Zarrelli M., Lopresto V. Modelling the damage evolution in notched omega stiffened composite panels under compression. Composites Part B-Engineering. 2017;126:60-71.

[70] Riccio A., Damiano M., Raimondo A., Di Felice G., Sellitto A. A fast numerical procedure for the simulation of inter-laminar damage growth in stiffened composite panels. Composite Structures. 2016;145:203-216.

[71] Campione G., La Mendola L., Monaco A., Valenza A., and Fiore V. Behavior in compression of concrete cylinders externally wrapped with basalt fibers. Composites: Part B. 2015;69:576-586.

[72] De Santis S., De Felice G., Napoli A., and Realfonzo R. Strengthening of structures with Steel Reinforced Polymers: A state-of-the-art review. Composites: Part B. 2016;104:87110. 